\title{
THE LOVIBOND COLOR SYSTEM
}

\section{A SPECTROPHOTOMETRIC ANALYSIS OF THE LOVIBOND GLASSES ${ }^{1}$}

\author{
By K. S. Gibson and F. K. Harris \\ WITH A PREFATORY STATEMENT \\ By Irwin G. Priest
}

ABSTRACT

A spectrophotometric analysis of the Lovibond glasses has been made as the first step in the development of methods of grading these glasses. The spectral transmissions from 380 to $750 \mathrm{~m} \mu$ and the integral transmissions for sunlight are presented in the paper in the form of tables and curves. The glasses studied include the 60 unit glasses from 1.0 to 20.0 of the red, yellow (also yellow 35.0), and blue series of the bureau set, in addition to 32 red and yellow glasses submitted by the American Oil Chemists' Society. The neutral combinations (red $\times$ yellow $\times$ blue) were also studied.

In spite of the extensive commercial use of this method of color grading, very little analytical study of the glasses, such as is given in the present paper, has been made. The data given herein show that, except for the erratic variations among the glasses which necessitate their calibration, the following relation holds true:

where

$$
-\log T_{\lambda}=k N+b
$$

$T_{\lambda} \equiv$ the transmission at a given wave length,

$N \equiv$ the Lovibond number for a given series,

$k, b \equiv$ constants.

This is the same relation as obtains with wedges or solutions if $N$ represents the thickness of the absorbing material.

The discussion touches briefly upon certain troubles found by users of the Lovibond system of color grading, illustrating especially both the need for and the difficulties involved in the regrading of the glasses themselves. Methods of grading will be developed in papers following this one.

1 This paper was presented in part at the tenth annual meeting of the Optical Society of America at Ithaca, October 29 to 31, 1925 (J. O. S. A. and R. S. I., 12, p. 481; May, 1926). 


\section{CONTENTS}

Prefatory statement

1. Description of the system.

2. Reasons for the investigation

3. Previous spectral analyses...

II. Spectral transmission _...

1. Experimental procedure-_... 14

2. Transmission as a function of wave length and Lovibond number............... 15

3. Neutral combinations

III. Integral transmission for sunlight

IV. Discussion _._. 19

1. Erratic variations

2. Reflection from the surfaces..... 19

3. Neutral combinations.......... 20

4. Comparisons with previous data_..... 21

V. Bibliography

VI. Red and yellow glasses, B. S. Test No. 41960 _...

VII. Tabulated values of transmission

VIII. Graphs. 


\section{PREFATORY STATEMENT}

\section{CONCERNING THE COOPERATIVE INVESTIGATIONS OF THE BUREAU OF STANDARDS AND THE MUNSELL RESEARCH LABORA- TORY}

This paper constitutes Partial Report No. 7 on Cooperative Investigations in Colorimetry by the Bureau of Standards and the Munsell Research Laboratory. It is the first to be published in the series of official publications of the bureau. As a matter of record the following list of the previous partial reports dealing with various phases of this cooperative investigation is given:

1. Priest, The colorimetry and photometry of daylight and incandescent illuminants * * *, J. O. S. A. and R. S. I., 7, pp. 1175-1209; 1923.

2. Priest, Apparatus for determination of color in terms of dominant wave length, purity, and brightness, J. O. S. A. and R. S. I., 8, pp. 173-200; 1924.

3. Priest, McNicholas, and Frehafer, Some tests of the precision and reliability of measurements * * * by the Koenig-Martens spectrophotometer, J. O. S. A. and R. S. I., 8, pp. 201-212; 1924.

4. Priest, Tuckerman, Ives, and Harris, The computation of colorimetric purity, J. O. S. A. and R. S. I., 9, pp. 503-520; 1924.

5. Priest, The computation of colorimetric purity, II, J. O. S. A. and R. S. I., 13, pp. 123-132; 1926.

6. Judd, The computation of colorimetric purity, J. O. S. A. and R. S. I., 13, pp. 133-154; 1926.

The above list does not include mere abstracts of papers read at various meetings. The following abstracts are mentioned as giving data or information which have as yet not received more adequate publication in complete papers:

1. Priest and Cottrell, The effect of various conditions upon the determination of the normal stimulus of gray, J. O. S. A. and R. S. I., Y, p. 73; 1923.

2. Priest, Preliminary data on the color of daylight at Washington, J. O. S. A. and R. S. I., 7, p. 78; 1923.

3. Priest, Apparatus for hue sensibility and visibility of energy, J. O. S. A. and R. S. I., 7, p. 99; 1923.

4. Priest, Special apparatus for determination of normal stimulus of gray with full field illumination, J. O. S. A. and R. S. I., 7, p. 100; 1923.

5. Priest, Gibson, and Munsell, A comparison of experimental values of dominant wave length and purity with their values computed from the spectral distribution of the stimulus, J. O. S. A. and R. S. I., 8, p. 28; 1924.

6. Priest, Gibson, and Harris, Measurements of illumination and color temperature at Washington during solar eclipse, January 24, 1925, Phy. Rev. (2), 25, p. 901; 1925.

7. Priest, Gibson, and Harris, Determination of the time of a solar eclipse from measurements of relative illumination, Phy. Rev. (2), 25, p. 902; 1925.

8. Priest, Gray skies and white snow, J. O. S. A. and R. S. I., 11, p. 133; 1925; and J. Wash. Acad., 15, p. 306; 1925. 
9. Priest, Standard artificial sunlight for colorimetric purposes, J. O. S. A. and R. S. I., 12, p. 479; 1926.

10. Priest, An experiment bearing on the adoption of a standard neutral stimulus in colorimetry, J. O. S. A. and R. S. I., 13, p. 306; September, 1926.

11. Priest and Brickwedde, Minimum perceptible colorimetric purity, J. O. S. A. and R. S. I., 13, p. 306; September, 1926.

12. Priest, Blue sky and white snow, J. O. S. A. and R. S. I., 13, p. 308; September, 1926.

The objective of this cooperative investigation is the establishment of the fundamental standards and data of colorimetry on a secure scientific basis. It is concerned largely with the psychophysical data of vision: Neutral stimulus ("white light"), brilliance sensibility, hue sensibility, saturation sensibility, the three elementary excitations, methods of observing and computing dominant wave length and purity, and the relations between these variables and hue and saturation. $^{2}$ For reasons given in the following text, this study of the Lovibond glasses has been undertaken incident to this more general investigation.

\section{CONCERNING THE OBJECTIVES OF THE PRESENT INVESTIGATION OF THE LOVIBOND GLASSES}

The standardization of the Lovibond glasses is being undertaken particularly at the request of those interested in their use in the vegetable-oil trade, and especial attention is being directed to the range of colors occurring in the color grading of these oils.

The objectives of this investigation are:

1. To specify in fundamental absolute terms the essential properties of the glasses (particularly the set known as B. S. 9940) as they now exist.

2. To specify in reproducible colorimetric terms a standard Lovibond scale which shall represent the present actual colors (B. S. 9940) as closely as possible, subject to the condition that the irregularities or erratic variations (which are obviously departures from what might be called an ideal scale) are eliminated.

3. To provide suitable methods for obtaining the equivalents of actual glasses in terms of the standard scale mentioned just above.

For years past the bureau has been the recipient of repeated and insistent demands that it "standardize," test, and certify Lovibond glasses. In the face of this demand the bureau has been very much in the position it would be in if, when asked to certify a pound weight, it were in the unfortunate position of having no official standard pound. The Lovibond glasses are made in England. As received in this country they are not reliable to the accuracy indicated by the fineness of their graduation. ${ }^{3}$ Even the glasses in one complete set ${ }^{4}$

\footnotetext{
${ }^{2}$ An outline of problems of visual psychophysics of particular importance to colorimetry is given in Appendix to B. S. Sci. Paper No. 417; August, 1921. This outline serves as a general guide for the investigation.

${ }^{3}$ Priest, Report of proceedings, fourth annual meeting of the Society of Cotton Products Analysts, Chicago, June, 1913, pp. 6-12. Priest, Report of proceedings, fifth annual meeting of the Society of Cotton Products Analysts, New Orleans, May, 1914, pp. 29-30. Priest, Report on calibration of sixteen Lovibond red glasses of nominal value 7.6, Cotton Oil Press, January, 1921. Cf. also sec. 4 below.

A B. S. Inventory No. 9940, obtained on B. S. Order No. 13644 and delivered to the bureau December 11, 1912.
} 
obtained by this bureau directly from the Lovibond establishment, The Tintometer (Ltd.), in England, are not consistent among themselves. For example, in this set the red glasses marked 6.0 and 7.0, respectively, are so nearly alike that, when compared (in combination with the same $35.0 \mathrm{Y}$ ), they can only be distinguished by the most careful observation and measurement. On the other hand, the difference between $7.0 \mathrm{R}$ and $8.0 \mathrm{R}$ in the same set is relatively very large. (For more specific statement, see sec. 3, below.) There are other irregularities almost as striking, but they need not be mentioned here in detail.

It is apparent that there is no standard other than the glasses as supplied by the Lovibond establishment, and that glasses so supplied are inconsistent among themselves.

The question then arises as to how standards may be established. We may now outline our tentative plans which are in course of execution.

If the "color" could be represented by a single experimental variable dependent upon the Lovibond number, and we should determine this variable for each of a series of the glasses, we could plot a curve showing graphically the relation between this variable and the Lovibond number. If the plotted points for all of the glasses in the series fell upon a "smooth curve," ${ }^{5}$ we would conclude that the glasses of this series were at least consistent among themselves, whatever other faults they might have. If, however, the plotted points were scattered, indicating only the general trend of a curve, while individual points departed from the curve by more than the sensibility of color discrimination, we would conclude that the glasses were not consistent among themselves. We could, however, adjust the irregularities by drawing among the scattered points the curve which would best represent all of them. If, then, for any glass we should determine the above-mentioned variable, the standard (true) Lovibond grade of that glass would be the number found by interpolation on this curve. It is obvious that the effect of this procedure would be to establish a standard depending upon all of the somewhat inconsistent individual glasses used to determine the curve, while smoothing out their individual erratic variations. Qualified by what is said below, this is, in effect, what we propose to do.

For example, all of the glasses in use in the oil trade in America might be collected at the Bureau of Standards and measured in order to establish this curve, which might then be said to define "the American adjusted normal Lovibond scale" for this series of glasses, each of which could then be regraded on this scale. However, such an

5 To within the sensibility of color discrimination. 
elaborate statistical procedure would hardly be worth the labor involved, and the Society of Cotton Products Analysts (now American Oil Chemists' Society) long ago indicated its willingness to accept the Bureau of Standards Lovibond glasses (B. S. 9940) as standard. The problem then reduces to adjusting the scale of this set by such a procedure as described above, qualified by what follows.

Unfortunately for the simplicity of calibration, color can not in general be adequately represented by one variable, but requires for its full and proper representation three variables. ${ }^{6}$ (It is possible in a purely empiric manner to do something in this way with only one variable. It is feasible in a limited way under conditions dictated by experimental acquaintance with the subject. This possibility is clearly illustrated in previous publications. ${ }^{7}$ However, such a procedure is too vitally dependent upon the tedious specification of purely arbitrary conditions to be considered a satisfactory fundamental method of calibration.)

In different aspects of colorimetry the three variables appear in different guises, and they may be differently envisaged for different purposes. For our present purpose we may consider that, for standard "white light" illumination and a normal observer, the color of any Lovibond glass or combination of glasses may be specified by the following three variables: ${ }^{8}$

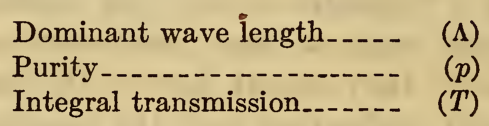

To illustrate how the calibration may proceed, let us suppose that $\Lambda, p$, and $T$ have been determined for each of the following Lovibond combinations of nominal grades: $35 \mathrm{Y}, 35 \mathrm{Y}$ and $1 \mathrm{R}, 35 \mathrm{Y}$ and $2 \mathrm{R}$, $35 \mathrm{Y}$ and $3 \mathrm{R}, 35 \mathrm{Y}$ and $4 \mathrm{R}$, etc., to $35 \mathrm{Y}$ and $20 \mathrm{R}$. We then construct three graphs showing, respectively:

$\Lambda$ as a function of $\mathrm{R}$

$p$ as a function of $\mathrm{R}$

and

\section{$T$ as a function of $\mathrm{R}$}

Suppose that these graphs have been constructed for the red glasses which are to define the scale and an unknown red glass is now submitted for test. We determine for it $\Lambda, p$, and $T$, and read its Lovibond grade from each of the three curves mentioned above. If these three

- See just below and also the following references: (1) Report of colorimetry committee, Optical Society of America, 1920-21, published in J. O. S. A. and R. S. I., 6, pp. 527-596; August, 1922. (Separate copies of this report may be obtained at 50 cents per copy from F. K. Richtmyer, business manager, J. O. S. A. and R. S. I., Cornell University, Ithaca, N. Y.) (2) Priest, J. O. S. A. and R. S. I., 8, pp. 173-200; January, 1924.

7 Priest, Report of proceedings, fifth annual meeting, Society of Cotton Products Analysts, New Orleans, May, 1914, pp. 29-30. Priest, Report on calibration of sixteen Lovibond red glasses, Cotton Oil Press, chemists section; January, 1921.

${ }^{8}$ For further explanation see J. O. S. A. and R. S. I., 8, pp. 173-200; January, 1924. 
values agree within suitable tolerances, this value may be taken as the standard Lovibond grade of this glass. If, on the other hand, the three values do not agree within suitable tolerances, the glass must be discarded.

At this point, however, we must consider the disturbing question of the normality of the observer who determines $\Lambda, p$, and $T$, if these are determined by direct observation. The standard curves can not be established by one observer and the tests made by another (unless elaborate tests have shown the observers to be quite alike in their color sense), and it is questionable whether reliance could properly be placed on a calibration dependent upon the observations of the same individual at widely different times in establishing the standard curves and in making the tests of unknowns.

Unless some way can be found to eliminate the "personal equation," we make the "standardization" depend upon the characteristics of vision of a certain individual. The "standardization" becomes unreliable as these characteristics change (as they well may with age) and it is of course utterly lost at his death.

Here appears the fundamental importance and utility of the measurements of "spectral transmission" as given in the present paper. These data are not personal; they describe solely and only properties of the glasses themselves.

\section{CONCERNING THE BEARING OF THE PRESENT PAPER ON THE STANDARDIZATION OF LOVIBOND GLASSES}

The first objective of the investigation of the Lovibond glasses ${ }^{9}$ is attained in the publication of the present paper. Whatever special or short-cut methods of calibration may be developed in the future it is certain that the data presented in this paper will remain the fundamental specification of the glasses in question. As such they are of the utmost permanent value. ${ }^{10}$

We may now merely indicate how these data may be utilized in order to attain the second and third objectives listed above.

The general investigation which the bureau and the Munsell Laboratory are now conducting aims to establish standard data which may be used to compute $\Lambda, p$, and $T$ (see sec. 2 above) for any glass, or combination of glasses, for a fictitious average normal observer, provided only we have given the spectral transmission. These computed values of $\Lambda, p$, and $T$ may then be used just as out-

\footnotetext{
- Namely, as listed above: "To specify in fundamental absolute terms the essential properties of the glasses * * * as they now exist."

10 "A spectrophotometric table, derived from at least 25 points (for a continuous spectrum), gives the only unique description of a color, and it appears probable to the writer that the requirements of precision technical color measurement are most likely to be met by the development of simple and rapid means of plotting and recording accurate spectrum plots of reflection or transmission characteristics," by H. E. Ives, J. Frank. Inst., p. 700; December, 1915. Cf. also Troland, Report of colorimetry committee, J. O. S. A. and R. S. I., 6, pp. 574-575; 1922; and Priest, Trans. I. E. S., 13, p. 41; 1918.
} 
lined in section 2 above, and we are relieved of the embarrassment of a standard dependent upon the characteristics and health of a particular person. This part of the standardization is now being carried on.

Numerous congruities between the data on spectral transmission and the irregularities in the graduation of the glasses already appear. For example, it is well established by many observations and tests that the red glasses marked 6.0 and 7.0 in B. S. set 9940 are so nearly alike as to be hardly distinguishable, while there is a notable difference between 7.0 and 8.0. Reference to Figures 1 and 9 in the present paper will show the cause for this. The colorimetric difference between $35 \mathrm{Y} 6 \mathrm{R}$ and $35 \mathrm{Y} 7 \mathrm{R}$, on the one hand, and $35 \mathrm{Y} 7 \mathrm{R}$ and $35 \mathrm{Y} 8 \mathrm{R}$, on the other, may be established with greater definiteness by computations from the spectral transmission than by direct observation. Preliminary computation (subject to slight revision) yields the following results for the "average normal observer":

\begin{tabular}{|c|c|c|}
\hline 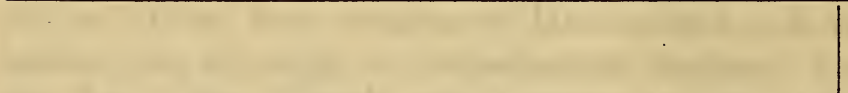 & $\begin{array}{l}35 \mathrm{Y} 8 \mathrm{R} \\
\text { minus } \\
35 \mathrm{Y} 7 \mathrm{R}\end{array}$ & $\begin{aligned} 35 \mathrm{Y} 7 \mathrm{R} \\
\text { minus } \\
35 \mathrm{Y} 6 \mathrm{R}\end{aligned}$ \\
\hline $\begin{array}{l}\text { Difference in dominant wave length } \\
\text { Difference in purity } \\
\text { Difference in integral transmission }\end{array}$ & $\begin{array}{l}2.0 \\
-.004(?)\end{array}$ & $\begin{array}{l}0.4 \\
-.002(?)\end{array}$ \\
\hline
\end{tabular}

Note especially the two differences in dominant wave length. At this point on the Lovibond scale the variable of chief importance is dominant wave length. The corresponding differences of dominant wave length by direct observation ${ }^{11}$ (mean of six individual observers) are as follows:

\begin{tabular}{l|r|r}
\hline & $\begin{array}{c}35 \mathrm{Y} 8 \mathrm{R} \\
\text { minus } \\
35 \mathrm{Y} 7 \mathrm{R}\end{array}$ & $\begin{array}{c}35 \mathrm{Y} \text { 7R } \\
\text { minus } \\
35 \mathrm{Y} 6 \mathrm{R}\end{array}$ \\
\hline Difference in dominant wave length $\ldots$ & 2.4 & 0.22 \\
\hline
\end{tabular}

Other illustrations of congruence between the spectral transmission and colorimetric observations might be pointed out, but to do so would exceed the limits of this prefatory note. It is planned to deal with these details in a separate paper.

In sections 2 and 3 of this preface I have merely attempted to set forth, in bare outline, shorn of all detail, the salient features of the plan for standardizing the Lovibond glasses. It is not expected that this skeleton outline will be very intelligible unless the reader is

"For method see J. O. S. A. and R. S. I., 8, pp. 173-200; 1924. 
somewhat well acquainted with the substance of the several papers cited in the footnotes. It is likely that minor details of the plan may be modified as the investigation proceeds.

\section{CONCERNING THE MAGNITUDE OF THE IRREGULARITIES WHICH HAVE BEEN PREVIOUSLY FOUND IN LOVIBOND GLASSES}

As stated in section 2 above, it has been found that the grading of the glasses as furnished is not reliable to the degree indicated by the fineness of their graduation.

It is worth while here to recall specifically just what has been found in this regard. For the sake of a definite brief statement, and because of the importance attached to this color in the oil trade, we shall consider only the irregularities in the red glasses as exhibited in the color about " $35 \mathrm{Y}$ 7R." The results of previous investigations made at this bureau ${ }^{12}$ may be summarized in this regard as follows: (1) The maximum deviations from ideal grading among a large number of glasses of nominal value 7.1 and 7.6 were found to be of the order of 0.5 of a red unit. (2) Deviations of this amount are not frequent, but occur only rarely (perhaps 1 in 10 or 20 of the glasses tested). (3) Irregularities of about 0.1 or 0.2 are common.

5. CONCERNING THE SENSIBILITY OF COLOR DISCRIMINATION AT 35.0Y 6R TO 8R, AND REASONABLE TOLERANCES IN THE COLOR GRADING OF OIL

With a standard scale established and the best means at hand for testing unknown glasses in terms of this standard at about $35.0 \mathrm{Y}$ $6 \mathrm{R}$ to $8 \mathrm{R}$, it will be possible to certify the equivalents of the glasses submitted for test to within about $0.1 \mathrm{R}$. It is to be observed, however, that certitude to this degree can only be attained by very careful work and by averaging a large number of observations. It seems reasonable to require that glasses to be used as control standards ${ }^{13}$ should be certified to this precision. When it is recalled that the maker's graduation appears to be reliable to within about $0.5 \mathrm{R}$ there seems to be but little choice between standardization to the precision just mentioned and no standardization at all beyond the maker's graduation.

Accuracy to within $0.2 \mathrm{R}$ or $0.3 \mathrm{R}$ would seem to be sufficient for glasses to be used only in the ordinary everyday work of grading oils.

\footnotetext{
12 Some published and some unpublished. For published reports giving more details than here summarized, consult (1) Priest, Report of proceedings fourth annual meeting, Society of Cotton Products Analysts, Chicago, 1913, pp. 6-12. (2) Priest, Report of proceedings fifth annual meeting, Society of Cotton Products Analysts, New Orleans, May, 1914, pp. 29-30. (3) Priest, Report on calibration of six. tcen Lovibond red glasses of nominal value 7.6, Cotton Oil Press; January, 1921.

${ }^{3}$ That is, glasses preserved as standards against which glasses for actual use in grading oil are to be checked. It is understood that the glasses of B. S. Test No. 41960 are to be adopted by the American Oil Chemists' Society as such control standards.
} 
If it is demanded that grading by different observers in different laboratories agree to within $0.5 \mathrm{R}$, then certainly very careful attention must be given to "standardizing" observers and conditions as well as to standardizing glasses.

6. CONCERNING DISCREPANCIES IN THE COLOR GRADING OF OIL DUE TO OTHER CAUSES THAN LACK OF UNIFORM STANDARDIZED GLASSES

This seems an opportune time for the writer of this preface to state his opinion that lack of uniformity in the glasses now in use is not the major cause of discrepancies said to occur between different laboratories in the color grading of oil. The need of standardization of the glasses has been greatly emphasized (perhaps relatively overemphasized) by the chemists concerned in this problem. The uniformity of the glasses used by different chemists in different places is, however, but one of the conditions to be satisfied in order to insure agreement of results in color grading of oil. It seems worth while to point out the following possible sources of discordant results: (1) Use of the glasses without rule as to the number of separate glasses used to match the oil. (2) Use of color comparators (tintometers) of widely different types. (3) Use of illuminants of widely different quality. (4) Color grading of oils by many persons whose color sense and power of color discrimination have never been tested.

Much remains to be done in standardizing the Lovibond glasses. To establish and maintain standard conditions for their use is still another problem. The present paper may be accepted as supplying the fundamental data which is indispensable to any intelligent attempt at standardization. Such data have never been available before. They are herewith made a matter of permanent record, available for ready reference at any time.

Bureau of Standards,

Irwin G. Priest.

Fune 26, 1926. 


\section{INTRODUCTION}

\section{DESCRIPTION OF THE SYSTEM}

An instrument known as the tintometer was devised by Joseph $\mathrm{W}$. Lovibond in the eighties for the "analysis, synthesis, matching, and measurement of colour" (1). ${ }^{14}$ As described in the advertising circular, it is a system "by means of which the depth of color in liquids and solids can be accurately measured in degrees, placed in their position in a permanent color scale, and registered for reproduction at any time. It consists of a graded series of standards made of colored glasses numbered according to their depth of color, and an instrument for holding the glasses and the object to be measured" $(6$, p. 6$)$.

There are three sets of colored glasses, red, yellow, and blue - the red glasses absorbing most strongly in the green, the yellow glasses in the blue-violet, and the blue glasses in the orange-red. ${ }^{15}$ Each set is numbered by the makers in units from 1.0 to 20.0 with many subdivisions, especially of the lower numbers. Glasses of higher grades may also be obtained. "Each ordinary scale consists of glass slips all of one color, but differing in depth, the divisions of difference being equal throughout ***" $(6$, p. 6$)$.

"The color units are not only of equal depth throughout each scale, but have also a color equivalence in relation to each other $* * *$ " (6, p. 6). "This equivalence of color value is accomplished when a normal white light can be gradually absorbed to extinction without the development of any color by successive additions of an equal number of units of the red, yellow and blue glass. *** The starting point of the system is the neutral tint unit, which is the quantity of normal white light absorbed by one red, one yellow, and one blue glass standard unit combined" (6, p. 7).

"The intervals between the units, or main divisions of the scales, are the smallest differences between which the normal vision can discriminate in the deeper shades of glass colors; these are subdivided into tenths as the shades get lighter, and ultimately into hundredths in the very light shades; in fact, increasing in minuteness as the discriminating power of the eye increases. The actual dimensions of the unit are arbitrary and of no real importance, so long as the divisions are equal both in dimensions and equivalence, and the subdivisions are sufficiently minute for the work required" (6, p. 9).

For further details regarding the instrument and its use reference may be made to the papers listed in the bibliography and to the discussion in the present paper.

\footnotetext{
14 The numbers in parentheses, followed occasionally by page references, refer to the bibliography, Section $\mathrm{V}$, of this paper.

is The principal coloring materials used in these glassses are gold for the red glass, silver for the yellow, and cobalt for the blue $(2$, p. 15$)$.
} 


\section{REASONS FOR THE INVESTIGATION}

The Lovibond tintometer has been used extensively in England and this country, the simplicity of operation and permanence of the standards making a strong appeal to the commercial world.16 Unfortunately, however, it has been found that the grading of the glasses, as supplied by the Lovibond establishment, is not reliable to the accuracy indicated by the fineness to which the scales are divided. Glasses which are marked the same may actually differ by several tenths of a unit; and even the glasses in a single setare found inconsistent among themselves. (See secs. 2 to 4 of prefatory statement for further details.)

Many of those using the Lovibond glasses have long realized the presence of such annoying discrepancies, with the result that many American users have requested the bureau to undertake the standardization of these glasses. This demand has been voiced particularly by the American Oil Chemists' Society. The recent development of a standard method of using the glasses (12) directs attention anew to the need of standardizing the glasses themselves. Quite aside from the merits or demerits of the Lovibond system as a thing in itself, it is apparent that, owing to its extensive and long established use in trade, a thoroughgoing investigation and standardization of the glasses will be of great service to the industries which make use of them. Another reason for undertaking this investigation is that the glasses, used alone or in combination with one another, furnish a large variety of colors suitable for investigations which the bureau is undertaking relative to the specification of color in terms of dominant wave length, purity, and integral transmission.

The data herein illustrated, therefore, make possible the analysis of the Lovibond system, assist in the comparison of computed and observed values for the three color variables just noted, with a possible revision of the three elementary excitations, and finally, through these studies, lead to the development of methods for the routine grading of the glasses.

It is to be understood that the publication of this paper in no way constitutes an indorsement or recommendation of the Lovibond method of specifying or reproducing colors nor of the theories given by the inventor in his descriptions of the system. It is merely an analysis of the particular set of Lovibond glasses which the Bureau of Standards possesses, a study of the system as it is.

10 The inventor states that his "colour standards * * * are now in use in over one thousand laboratories, and no question of their practical accuracy arises" (8, p. 7). 


\section{PREVIOUS SPECTRAL ANALYSES}

In spite of the many users of this system of color specification few have made any study of the spectral characteristics of the glasses. The inventor himself has consistently avoided any analysis such as is herein given. In fact, the authors have found but two references giving information of this kind.

The first of these is by Edridge-Green (3), who gives "absorption ${ }^{17}$ curves" from 360 to $760 \mathrm{~m} \mu$ for one red, one yellow, and one blue glass ${ }^{18}$ and qualitative spectral analyses of several combinations of glasses.

A more extensive investigation of the glasses has been made by Lowry and McHatton (10). They give spectral curves for each of the glasses-red 10.0, yellow 10.0, and blue 10.0-and also for the combined three in series. They plot density (logarithm of the ratio of incident to transmitted light) against wave length over the range from 460 to $700 \mathrm{~m} \mu$.

They also give curves showing the relation between density and Lovibond number (from 0 to 20.0) for a single wave length for each color; that is, for $480 \mathrm{~m} \mu$ in the case of the yellow glasses and for $530 \mathrm{~m} \mu$ for the red and blue glasses. Quoting the authors: "**** a very close linear relationship was found for the range of numbers from 3 to 20; but the straight lines instead of passing through the origin, would (if produced) cut the line of zero density at a point nearly two units to the left ${ }^{19}$ of the origin on the scale of numbers. The measurement of the lower densities is less easy, but careful tests have enabled us to trace the way in which the density curves are made to pass through the origin giving rise to marked curvature of the lines, so that the linear relationship is much less exact for the lower than for the higher numbers of the three series. It may be added that in all these measurements the filter was compared with a colourless glass, in order to cancel out the effects due to loss of light by reflection" (10, pp. 196-197). There would seem to be some question as to the accuracy of the data upon which the above conclusions are based, since the authors state that "it was found that the composite curve for three filters in series agreed most closely with the sum of the constituent density-curves when the filters were measured separately against a single colourless glass and the three together without any" (10, p. 197).

In a later paper (11) the same authors illustrate the variability in the density curves for two red glasses of the same Lovibond number.

17 The unit of absorption is not stated.

18 The legends of two of these three figures have been confused. Present Figure 1 should be Figure 3 and should read "Absorption curve of the yellow glass " " " while Figure 3 should be Figure 1 and should read "Absorption curve of the rose glass " " "

10 That is, at Lovibond number, -2 . 


\section{SPECTRAL TRANSMISSION}

\section{EXPERIMENTAL PROCEDURE}

Several methods were used to obtain the data illustrated herein. Visual measurements ${ }^{20}$ were made on the König-Martens spectrophotometer at every $10 \mathrm{~m} \mu$ from about 450 to $690 \mathrm{~m} \mu$. Measurements were also made at every $10 \mathrm{~m} \mu$ photo-electrically from 400 to 500 or $540 \mathrm{~m} \mu$ and thermoelectrically from 600 or 650 to $750 \mathrm{~m} \mu$. To assist in extrapolating from 400 to $380 \mathrm{~m} \mu$, photographic measurements were made on several of the glasses. Descriptions of these methods of measuring spectral transmission have been previously published ${ }^{21}$ and will not be further noted here.

The overlapping methods eliminate the possibility of any considerable error in the adopted transmission data. The agreement ordinarily obtained between methods was often lacking, however, because of the poor optical condition of many of the samples. These are in all cases flashed glasses, and strias and other imperfections are of ten readily visible. The body glass is also in many cases wedge shaped. The yellow samples seemed the worst in these respects, and two or more independent sets of visual measurements were, therefore, made on each sample in addition to those by the auxiliary methods. Check measurements were also made on R 1.0, Y 35.0, ${ }^{22}$ and others where any question arose as to the reliability of the data.

After the final transmission data had been adopted it seemed advisable to make a further independent check with homogeneous light of certain wave lengths. Accordingly, transmission measurements, using the mercury arc as a light source, were made on the König-Martens spectrophotometer at 404.7 and $435.8 \mathrm{~m} \mu$ for the yellow glasses having transmissions greater than about 0.01 , at 435.8 and $546.1 \mathrm{~m} \mu$ for all the red glasses, and at $546.1 \mathrm{~m} \mu$ for all the blue glasses. These measurements agreed very well with the adopted values. In but one case, B 2.0, did it seem necessary to make further measurements, and a revised set of values was thereupon adopted for this glass. As a result the authors feel confident that the erratic variations in the adopted transmission data illustrated below are largely a result of real variations from the ideal grading (or numbering) of the glasses.

The unit series of glasses from 1.0 to 20.0 (B. S. No. 9940) were chosen for measurement. Yellow 35.0 (B. S. No. 10289 B) was also included because of its use with the reds in the grading of vegetable oils.

${ }^{20}$ Some of these measurements were made by J. K. Cromer, of the staff of the colorimetry section.

21 B. S. Tech. Paper No. 148; 1920. B. S. Sci. Paper No. 440; 1922 . J. O. S. A. and R. S. I., 7, pp. 693-704; 1923; J. O. S. A. and R. S. I., 8, pp. 201-212; 1924.

${ }_{22} \mathrm{R} 1.0$ refers to red glass of grade 1.0, Y 35.0 to yellow glass of grade 35.0, and so on throughout the paper. 


\section{TRANSMISSION AS A FUNCTION OF WAVE LENGTH AND LOVIBOND NUMBER}

With the values of spectral transmission adopted as explained above and tabulated in Section VII, the curves for the unit glasses from 1.0 to 20.0, red, yellow, and blue, have been plotted ${ }^{23}$ on a logarithmic scale. These are shown ${ }^{24}$ in Figures 1 to 3, Sec. VIII. The curve for $\mathrm{Y} 35.0$ is also shown in addition to the hypothetical zero curves (dot and dash lines) obtained as explained below. Where values of transmission below 0.01 are considered reliable, they are multiplied by 100 and plotted as dotted lines.

The approximately equal spacing between the curves of successive numbers is immediately obvious. To illustrate this better, Figures 4 to 6 were plotted, showing transmission as a function of Lovibond number at various wave lengths. The open circles are values taken from Tables 1 to 3, and illustrated by the curves of Figures 1 to 3 ; the solid circles are the independent values obtained with the mercury arc, as previously explained. The linear relation is unmistakable in the case of all wave lengths which are of importance in the determination of the color, in spite of the erratic variations which may often be noted.

Expressing this relation in the form of an equation, we have, for any given wave length,

where

$$
-\log T_{\lambda}=k N+b
$$

$T_{\lambda} \equiv$ the transmission at the given wave length,

$N \equiv$ the Lovibond number for a given series,

$k, b \equiv$ constants.

The value of $k$ depends primarily on the spectral densities of the unit Lovibond glasses, that of $b$ in most cases on the loss of light by reflection at the surfaces. This is, of course, the same equation as is obtained with solutions or wedges, if $N$ represents the thickness of the absorbing material, this general law being often known as Lambert's law of transmission.

An extrapolation of the curves of Figures 4 to 6 back to $N=0$ gives the data from which curves No. 0 were plotted in Figures 1 to 3. In the case of the red and blue glasses this hypothetical No. 0 glass is practically neutral, completely transmitting except for the loss by reflection. In the case of the yellow series, however, a glass having a transmission equivalent to curve No. 0 would be not neutral but distinctly yellowish.

\footnotetext{
${ }^{23}$ The illustrations for this paper were prepared by C. L. Snow.

${ }^{24}$ Values of transmission (ratio of transmitted to incident energy) are given by the left-hand ordinate, while at the right the negative logarithms, base 10, may be noted from the linear scale. These negative logarithms are often called densities or opacities.
} 
An inspection of the glasses graded between 0.0 and 1.0 showed that there was no reason to expect any consistent deviation from the linear relation for these grades in the case of the red and blue glasses. The lowest grades of the yellow glasses seemed, however, to be more nearly neutral than was to be expected on the basis of the linear relation and No. 0 curve established from the data of glasses 1.0 to 20.0. Accordingly, measurements of transmission were made with the mercury 435.8 and $404.7 \mathrm{~m} \mu$ lines for the yellow glasses graded as tenths or hundredths of the first unit. The values so obtained are plotted in Figure 7. The continuous straight lines there plotted are identical with those of Figure 5, and the deviations of the values from these straight lines are readily seen. ${ }^{25}$. It is interesting to note that another straight line may be plotted through these values below grade 1.0, as is shown by the dotted lines. These lines give a transmission of about 0.9 for the hypothetical No. 0 glass, as in the case of the red and blue series.

In Figure 8, the straight lines of Figure 5 are extended for comparison with the data for Y 35.0. Graded on this basis Y 35.0 might be numbered 2 or 3 units higher, but it is, of course, uncertain, the intermediate glasses not being available, whether this discrepancy indicates a failure of the linear relation for these high grades or is merely an erratic variation similar to those of Figure 5. (Cf. Section VI and fig. 14, where the linear relation is shown to hold through grade 35.0 .)

In Figure 9 are plotted the data obtained by multiplying the spectral transmission of $\mathrm{Y} 35.0$ by that of the red glasses from 1.0 to 20.0 , respectively. This represents a srale quite widely used in the color grading of cottonseed oil and other vegetabie oils. The curves of Figure 9 have no particular significance except in connection with this convention in the commercial grading of these oils.

\section{NEUTRAL COMBINATIONS}

As noted in the introduction equal grades of the three colored glasses in combination result in a "neutral tint." The combined transmission (computed) of the corresponding red, yellow, and blue glasses, from 1.0 to 20.0, respectively, are given in Table 4 and plotted in Figure 10. Curve No. $0{ }^{26}$ is also given, the product of the hypothetical curves No. 0 of Figures 1 to 3. To avoid confusion, values of transmission below 0.01 are not plotted to a magnified scale as was done in the other figures.

\footnotetext{
${ }^{25} \mathrm{It}$ may be objected that the continuous lines of Figures 5 and 7 do not best fit the ralues for $404.7 \mathrm{~m} \mu$. An alternative line is drawn (dashed) in Figure 7, but the deviations from this line of the values below grade 1 are still very definite. Curve No. $0^{\prime}$ of Figure 2 is plotted on the basis of this alternative line, having a transmission of 0.62 instead of 0.50 at $404.7 \mathrm{~m} \mu$.

${ }^{26}$ Curve No. $0^{\prime}$ is the product of curves No. 0 of Figures 1 and 3 and No. $0^{\prime}$ of Figure 2.
} 
The ideal neutral glass or combination would have, of course, a transmission curve parallel to the wave-length axis. The deviations from the ideal, as shown by the curves of Figure 10, are perhaps little worse than found in many "neutral" glasses. The low values in the violet and the high values in the red may be noted.

\section{INTEGRAL TRANSMISSION FOR SUNLIGHT}

The integral transmission, $T$, of a transparent, nondiffusing glass may be defined as

where

$$
T=\frac{\Sigma E_{\lambda} V_{\lambda} T_{\lambda}}{\Sigma E_{\lambda} V_{\lambda}}
$$

$E_{\lambda} \equiv$ relative spectral energy of the light source.

$V_{\lambda} \equiv$ relative spectral visibility.

$T_{\lambda} \equiv$ spectral transmission.

Computations by this equation were made on all the glasses for which the complete spectral transmission data had been obtained. The quantities $E_{\lambda} V_{\lambda}$ and $E_{\lambda} V_{\lambda} T_{\lambda}$ were computed at every $10 \mathrm{~m} \mu$ and the summations carried out over the range from 390 to $750 \mathrm{~m} \mu$. The following data were used:

$T_{\lambda}$, the data of Figures 1 to 3, and 10, and Tables 1 to 4 .

$\nabla_{\lambda}$, values recommended in Bureau of Standards Scientific Paper No. $475,{ }^{27} 1923$, and provisionally adopted by the International Commission on Illumination, meeting at Geneva in July, $1924 .^{28}$

$E_{\lambda}$, Priest's artificial sunlight, ${ }^{29}$ a spectral distribution approximating average noon sunlight at Washington.

Values of integral transmission so computed are given in Tables 1 to 4 and plotted in Figure 11 as a function of Lovibond number. It will be noted that there is not, in general, a linear relation between these variables, ${ }^{30}$ although, in the case of the yellow glasses and the neutral combinations, straight lines (dashed) fit the data about as well as the curved lines. The red and blue series show decided curvature.

It is, perhaps, a matter of interest to consider further whether a straight or a curved line best fits the values in the case of the neutral combinations. Having given the linear curves of Figures 4 to 6 for the three separate series, linear curves must, of course, result from their combination. If these combined red, yellow, and blue glasses gave truly neutral transmissions (that is, transmissions independent of wave length) for all the grades, then the integral transmissions for

\footnotetext{
${ }^{27}$ Gibson and Tyndall, B. S. Sci. Papers, 19, pp. 131-191; 1923. Recommended values, p. 174, last column.

${ }^{28}$ Cf. Trans. I. E. S., 192, pp. 613-614; 1924; and Recueil des Travaux de la Commission Internationale de l'Éclairage, Sixıème Session, pp. 67 and 232.

${ }^{29}$ Priest, Irwin G., Phys. Rev. (2), 11, p. 502; 1918; J. O. S. A. and R. S. I., 12, pp. 479-480; May, 1926.

${ }^{30} \mathrm{It}$ is a well-known fact that, in general, Lambert's law of transmission is not valid for the integral transmission of selective media.
} 
light at any color temperature, when plotted against Lovibond number, must give a straight line. The tendency for the neutral values of Figure 11 to fall upon a curved rather than a straight line is doubtless a result of the departures of the spectral transmission curves of Figure 10 from the truly neutral condition. The effect is illustrated by the curves for the red and blue glasses in Figure $11 .^{31}$

While the values of integral transmission for the neutral combinations of the higher grades seem to fit a straight line better than a curved one, the deviations of the plotted values of Figure 11 from the curved line above grade 14.0 may be no greater than can be accounted for by errors of measurement (considering, as previously noted, the optical condition of the samples) or the erratic variations among the glasses themselves. In this connection, two checks of the integral transmission of the neutral combinations may be noted.

1. As above stated, the energy distribution of Priest's artificial sunlight was the basis of the computed values of integral transmission shown in Figure 11. Inasmuch as the "equivalence" of the glasses was established with the uniform diffused light of white sea fog $(8$, p. 10), having a color temperature probably between 6,000 and $7,000^{\circ} \mathrm{K}$., it seemed desirable to recompute some of the values on this basis. Accordingly, the integral transmission for light of $7,000^{\circ} \mathrm{K}$. was computed in the case of the neutral combinations Nos. 1.0, 10.0, and 20.0. The results are shown in Figure 11 (open circles with lines attached) and show that no appreciable change in the values is introduced by this difference in energy distribution of the source.

2. As a further check, values of integral transmission were directly determined by flicker photometry for the neutral combinations from 1.0 to 14.0 for Priest's artificial sunlight. The values thus experimentally obtained are shown likewise in Figure 11 (solid circles). They show the same tendency to curvature that the computed values do. The average deviation of these observed values from the computed ones for the neutral grades from 1.0 to 12.0 is +2.8 per cent. This is not considered outside of the various possible experimental errors. Furthermore, the color of the combined red, yellow, and blue glasses is distinctly reddish (especially when compared with the original white light in a photometric field) for all but the lower grades, and this, combined with the fact that the observer who made the measurements of integral transmission is red sensitive, may account for some of the deviation between observed and computed results. The reversed Purkinje effect, found with flicker photometry at low brightnesses, is probably the cause for the increasing divergence shown at grades 13.0 and 14.0.

\footnotetext{
${ }^{31}$ A similar curvature may be noted for the yellow glasses, Figure 15.
} 


\section{DISCUSSION}

\section{ERRATIC VARIATIONS}

The present data serve to illustrate many of the troubles encountered in the use of the Lovibond system of color grading. Only a partial discussion of these can, however, be given pending the completion of the investigation of the dominant wave lengths and purities of the colors obtained with these glasses.

Examination of Figures 4 to 8 and 12 to 14 seems to justify the following hypothesis: (1) The ideal or normal relation between Lovibond number and transmission is shown by the straight lines in these graphs and is thus represented by special cases of Lambert's law of transmission. (2) The small departures from this relation in the case of individual glasses may be regarded as due to inaccuracies in grading the glasses.

These erratic variations from the normal relation, which are illustrated in this paper, indicate in a qualitative way both the need for calibration of Lovibond glasses and the difficulties in the way of such calibration. Color has three characteristics-hue, saturation, and brilliance ${ }^{32}$ - which may be correlated with the physical quantities of dominant wave length, purity, and brightness. The last of these in the case of glasses is further correlated with their integral transmissions. A Lovibond glass which is not properly graded may be incorrect as regards any one of the above three variables, or any two of them in combination, or all three together. For example, red glasses 6.0 or 7.0 , and 16.0 or 17.0 (fig. 1), will certainly depart from the attempted ideal as regards hue; $\mathrm{R} 20.0$ will certainly be high in both purity and integral transmission; and Figure 11 gives information as to the variations of this particular set from the proper integral transmissions. Further discussion of these variations seems profitless here, however, and the question of grading the improperly classified glasses must, of course, be reserved for a future publication, when the further data are available.

\section{REFLECTION FROM THE SURFACES}

Passing over the questions as to whether or not the best available kind of glass has been chosen for the three colors, and as to the extent to which all colors may be duplicated by combinations of these glasses, we may note one or two other factors which have caused more or less serious trouble in the use of the system.

The most important of these is the loss of light by reflection at the surfaces of the glasses. There would seem to be no doubt as to how a given series of glasses was built up. Reference to Figures 4 to 6 indicate that, in general, glasses Nos. $1+1=2+0,2+1=3+0$,

32 O. S. A. Colorimetry Report, J. O. S. A. and R. S. I., 6, p. 534; August, 1922. 
$3+1=4+0=2+2$, etc. It would seem very difficult to obtain series of as high precision even as those shown in these figures without the use of a No. 0 glass. Perhaps the inventor used such a glass, for he states, in answer to a question asked after one of his earlier lectures, that "if he had to deal with two glasses against one, he added a white glass to the one, so as to equalize the number of surfaces on each side" ( 2, p. 15). On the other hand, in a more recent publication, he says, in describing the method for obtaining equality of the unit division, "Two slips of red glass in a light shade were made exactly equal in colour, and considered as initial units; these were then superimposed and matched by a single glass, which was then considered as of two units, this and one of the initial units were superimposed, and matched by a single glass of three colour units, and so on, until a progressive red scale was constructed, ranging in intensity from 0.01 to 20 units. It was found that the superimposition of two glasses did not visually disturb equivalence, therefore only two glasses were used for each observation in constructing the scale. The yellow and blue scales were similarly constructed" (8, pp. 29-30).

Regardless of this, however, in the practical use of the instrument to match test colors the loss of light by reflection makes it possible to match the same color by different combinations of glasses. This has been noted by Knapp (5, p. 1343) and others. The "Instructions for using the instrument" $(6, p .13)$ totally ignore this point. Only in case some such system is adopted as that by Bailey (12) will the values obtained be unique.

\section{NEUTRAL COMBINATIONS}

The high transmission of the neutral combinations in the far red (fig. 10) explains, of course, the gradual change in color from approximately neutral to reddish as the higher grades of $\mathrm{R} \times \mathrm{Y} \times \mathrm{B}$ are reached. This has caused the inventor considerable annoyance and speculation (for example, 4, p. 104; 8, p. 41), but is inherent in the use of cobalt blue glass in which the far red band has not been subdued by the addition of copper oxide in the glass.

The importance of a standard light source in the use of the instrument is quite properly noted in the various descriptions of the system, and because of this far red transmission the use of sources with a preponderance of red, such as incandescent lights, or of very intense sources, such as direct sunlight, were not found suitable. "Ordinary daylight" is recommended, "north light" being preferable $(6, p .13)$. The light used by Lovibond in establishing the equivalence of his red, yellow, and blue units was "that of a so-called sea fog away from the contaminating influence of towns. The white fog of Salisbury Plain was used as being most available" $(8$, p. 10). 


\section{COMPARISONS WITH PREVIOUS DATA}

The linear curves of Figures 4 to 6 show no sign of a break near Lovibond number 3.0 as found by Lowry and McHatton (Cf. Sec. I, 3). The only failure of the linear relation between $-\log T_{\lambda}$ and Lovibond number is that already noted for the yellow glasses (fig. 7), where the values above and below No. 1 fall into different slopes. Moreover, as already noted, the fact that the spectral densities $\left(-\log T_{\lambda}\right)$ are linear functions of the Lovibond number can not be taken to mean that the integral densities $(-\log T)$ are necessarily likewise linear functions of the number, as is illustrated by Figures 11 and 15. This is not made clear by Martin, who refers to the work of Lowry and McHatton in discussing the Lovibond system of color grading. ${ }^{33}$

Lowry and McHatton (11, p. 353) give a value of 1.5 as the (integral) density of the combination $\mathrm{R} 10.0 \times \mathrm{Y} 10.0 \times \mathrm{B} 10.0$. The present data give a value of about 1.42 (fig. 11). The following quotation from these authors should, perhaps, not pass without correction: "*** the density of the combination of three No. 10 slides was 1.5. A total Lovibond number of 30 is therefore equal to a density of 1.5 , and each unit on his numerical scale is therefore equivalent to a density of about 0.05 " (11, p. 353). The combination R 10.0 $\times \mathrm{Y} 10.0 \times \mathrm{B} 10.0$ does not give a Lovibond number of 30 but a "neutral tint" of 10.0 units (8, pp. xii and 22). Furthermore, the same grades of the different colors while being "equivalent" have entirely different spectral and integral densities, as already illustrated, and the relation between density and Lovibond number is thus different for each series of glasses.

\section{BIBLIOGRAPHY}

It has not been attempted to note here all of the numerous papers that have been published regarding the Lovibond system. Only those are given which are of importance for the purposes of this paper.

1. Lovibond, Joseph W., The tintometer-a new instrument for the analysis, synthesis, matching, and measurement of colour, J. Soc. Dyers and Colourists, 3, pp. 186-193; 1887.

2. Lovibond, J. W., On a new method of colour analysis by means of the tintometer, J. Soc. Chem. Ind., 9, pp. 10-15; 1890.

3. Edridge-Green, F. W., The scientific value of Lovibond's tintometer, J. Soc. Arts, 40, pp. 213-221; 1891-92.

4. Lovibond, J. W., Measurement of Light and Colour Sensations, George Gill \& Sons, London; 1893.

5. Knapp, Arthur W., The interpretation of colour values obtained by Lovibond's tintometer, J. Soc. Chem. Ind., 29, pp. 1343-1344; 1910.

6. The Tintometer (Ltd.), The Colour Laboratories, Salisbury, England; 1912.

33 Martin, L. C., Colour and Methods of Colour Reproduction, pp. 110-112. Blackie \& Son (Ltd.), London; 1923. 
7. Priest, Irwin G., Color specifications, Rep. Proc. Fourth Ann. Meet. Soc. Cotton Products Analysts (Chicago, June 21, 1913), pp. 6-13.

8. Lovibond, Joseph W., Light and Colour Theories. E. \& F. N. Spon (Ltd.), London; Spon \& Chamberlain, New York; 1915.

9. Priest, Irwin G., Report on calibration of sixteen Lovibond red glasses, Cotton Oil Press; January, 1921.

10. Lowry, T. Martin, and McHatton, L. P., A comparative study of methods used for the measurement of colour. J. Oil and Colour Chem. Assn., 4, pp. 189-204; 1921.

11. Lowry, T. Martin, and McHatton, L. P., Further experiments on the measurement of colour. J. Oil and Colour Chem. Assn., 5, pp. 351-353; 1922.

12. Bailey, H. S., A new type of color-comparator. Am. Oil Chem. Soc. J. Oil and Fat Industries, 2, pp. 8-13; January, 1925.

\section{RED AND YELLOW GLASSES, B. S. TEST No. 41960}

Since the completion of the above investigation, measurements have been made upon some Lovibond glasses ${ }^{34}$ submitted for calibration by the Southern Cotton Oil Co. through H. S. Bailey, B. S. Test 41960. These glasses are to be used as reference standards by the American Oil Chemists' Society. A spectrophotometric analysis has been made of these glasses, as was done with the bureau set and described in Sections II and III, and it becomes of immediate interest and importance to compare the data obtained on the two sets.

Measurements were in this case made solely on the König-Martens spectrophotometer, with the mercury lines 404.7, 435.8, 491.6, 546.1, and $578.0 \mathrm{~m} \mu$ for all the glasses, and with the usual source between 460 and $720 \mathrm{~m} \mu$ for the red glasses and 420 and $720 \mathrm{~m} \mu$ for the yellow glasses. Extrapolation to 380 and $750 \mathrm{~m} \mu$ was facilitated by comparison with the curves for the bureau glasses. Each glass was in the instrument at least twice, once with the mercury light and once with the other source. If the results did not check closely enough, further measurements were taken. The specimens were of the same poor optical quality as the bureau set.

In general, the values of transmission obtainea on the same numbered glasses of the two sets are sufficiently similar to make further illustration as in Figures 1 to 3 useless. Detailed comparisons to any desired extent may be made from the values of spectral transmission tabulated in Section VII. Some very close agreements and some rather wide divergences may be noted.

Probably the most interesting comparisons of the two sets by means of the present data may be made in connection with the linear relations shown in Figures 4, 5, and 8. The straight lines of these figures, if a sufficient number of wave lengths was used, should give an ideal set of transmission curves with the erratic deviations eliminated.

${ }^{34}$ The following glasses were submitted: Reds, 0.10 to 0.90 by tenths, and 1.0 to 10.0 by units; yellows 1.0 to 10.0 by units, and Nos. 20.0,30.0, and 35.0 . 
And if the more than 1,000 sets of Lovibond glasses that have been issued have really been kept to a common basis on the average, allowing for the accidental individual variations, then the values obtained on the glasses of B. S. Test No. 41960 should fall upon these straight lines of Figures 4, 5, and 8 as closely as do the values obtained with the bureau glasses, on the basis of which the straight lines were drawn.

Accordingly, in Figures 12, 13, and 14 are plotted the identical straight lines of Figures 4, 5, and 8, respectively, based upon the bureau glasses, No. 9940. The circles of Figures 12, 13, and 14, however, are the transmissions obtained with the glasses of B. S. Test No. 41960.

The following points may be noted:

1. There is, on the average, fairly close agreement, the straight lines in most cases fitting the values obtained with the glasses of B. S. Test No. 41960 as well as they do the bureau glasses.

2. The values for Y 35.0, B. S. Test No. 41960, fit the lines better than do those for the bureau glass of the same grade. The linear relation apparently holds for the yellows through grades 30.0 and 35.0 .

3. At wave lengths below $440 \mathrm{~m} \mu$ the yellow glasses of B. S. Test No. 41960 would give straight lines of a little greater slope than those plotted, and the No. 0 curve resulting would be similar to the $0^{\prime}$ curve of Figure 2, perhaps even slightly higher.

4. In most cases the values for the red glasses fit the curves fairly well. The tendency of the values at $500 \mathrm{~m} \mu$ to be high and those at 550 (and 546.1) $\mathrm{m} \mu$ to be low illustrates a shift of the absorption band to longer wave lengths in some cases.

5. To avoid confusion, only the values at $530 \mathrm{~m} \mu$ for the red glasses 0.10 to 0.90 are plotted. In this case, as with the unit grades, the values at 546.1 and $550 \mathrm{~m} \mu$ average low. Those for the other wave lengths fit fairly well, except in the case of $R 0.80$, which is low throughout.

A similar comparison of the two sets may be made in the case of the integral transmissions. In Figure 15, upper half, the continuous line is identical with the "red" curve of Figure 11 based on the bureau glasses No. 9940, while the open circles are the integral transmissions, computed as before, for the red glasses of B. S. Test No. 41960. The dotted curve is based solely on these latter values.

In the case of the yellow glasses the exact form of the curve of Figure 11 was somewhat uncertain. Accordingly, the complete data for both sets are plotted in Figure 15, lower half, and the scale compressed so that the values for Y 30.0 and Y 35.0 may be included. The continuous line is identical with the "yellow" curve of Figure 11 and apparently represents the data for glasses Nos. 1 to 10 of B. S. 
Test No. 41960 satisfactorily. On the basis of the more complete data, however, the dashed curve should supersede the continuous curve above Y 13.0.

\section{TABULATED VALUES OF TRANSMISSION}

In order that further study may be made by any one interested, the complete spectral and integral transmission data are given in Tables 1 to 6 . In general, the absolute value tabulated is somewhat uncertain in the last figure given, except in the case of the computed values of Table 4, which have been carried uniformly to four decimal places regardless of the significant figures. 


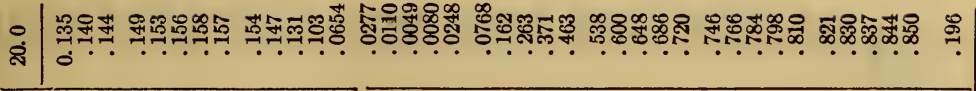

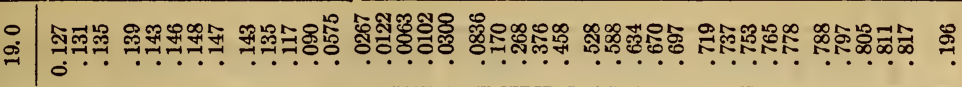

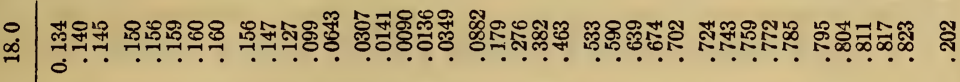

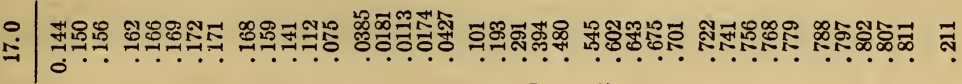

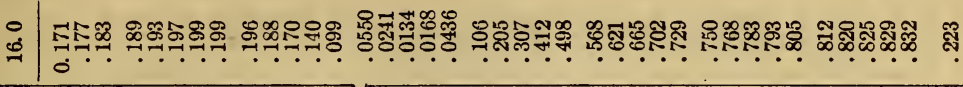

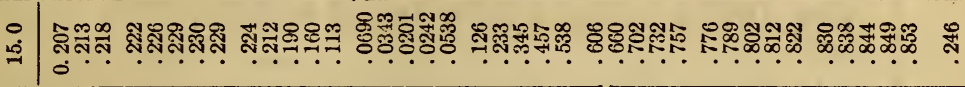

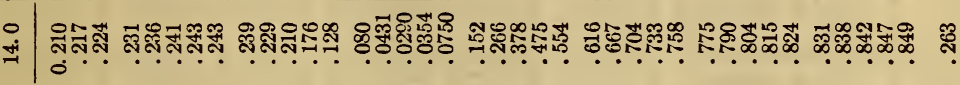

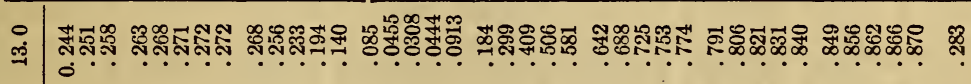

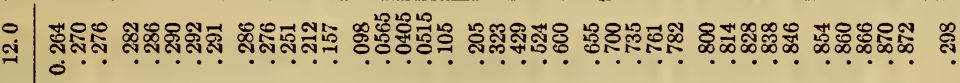

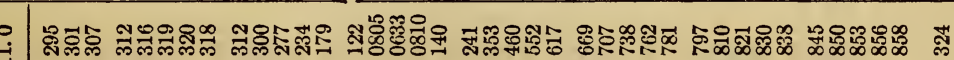

$\Rightarrow$ a

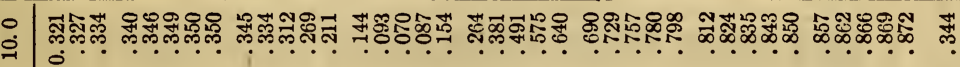

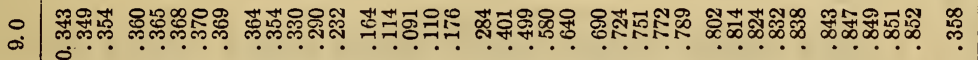

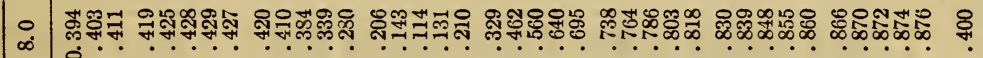
0

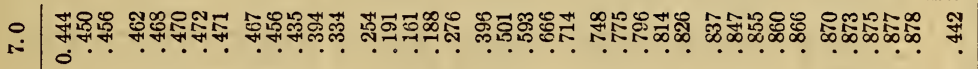

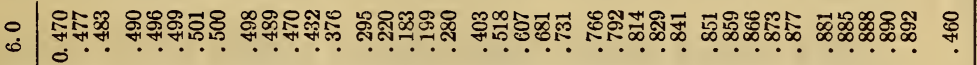

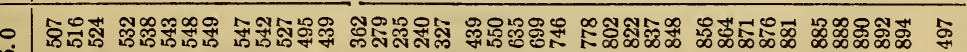

O)

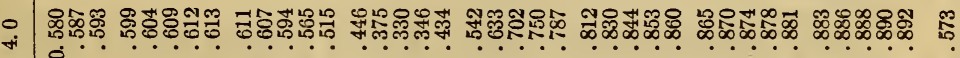

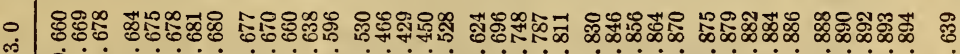

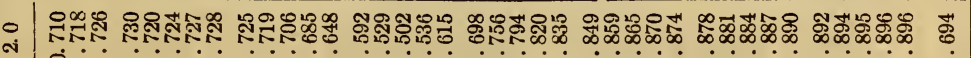

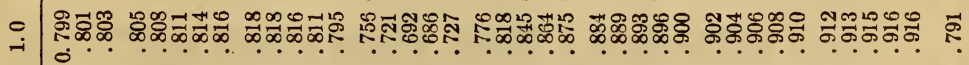

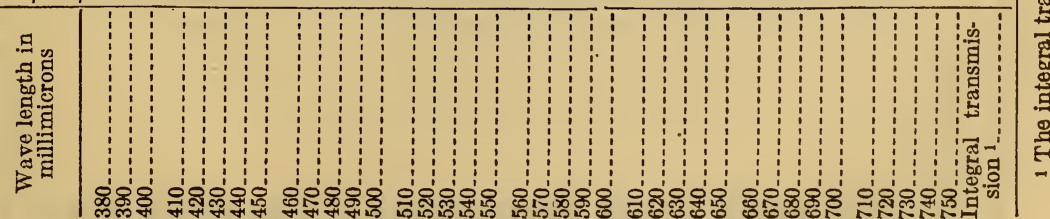




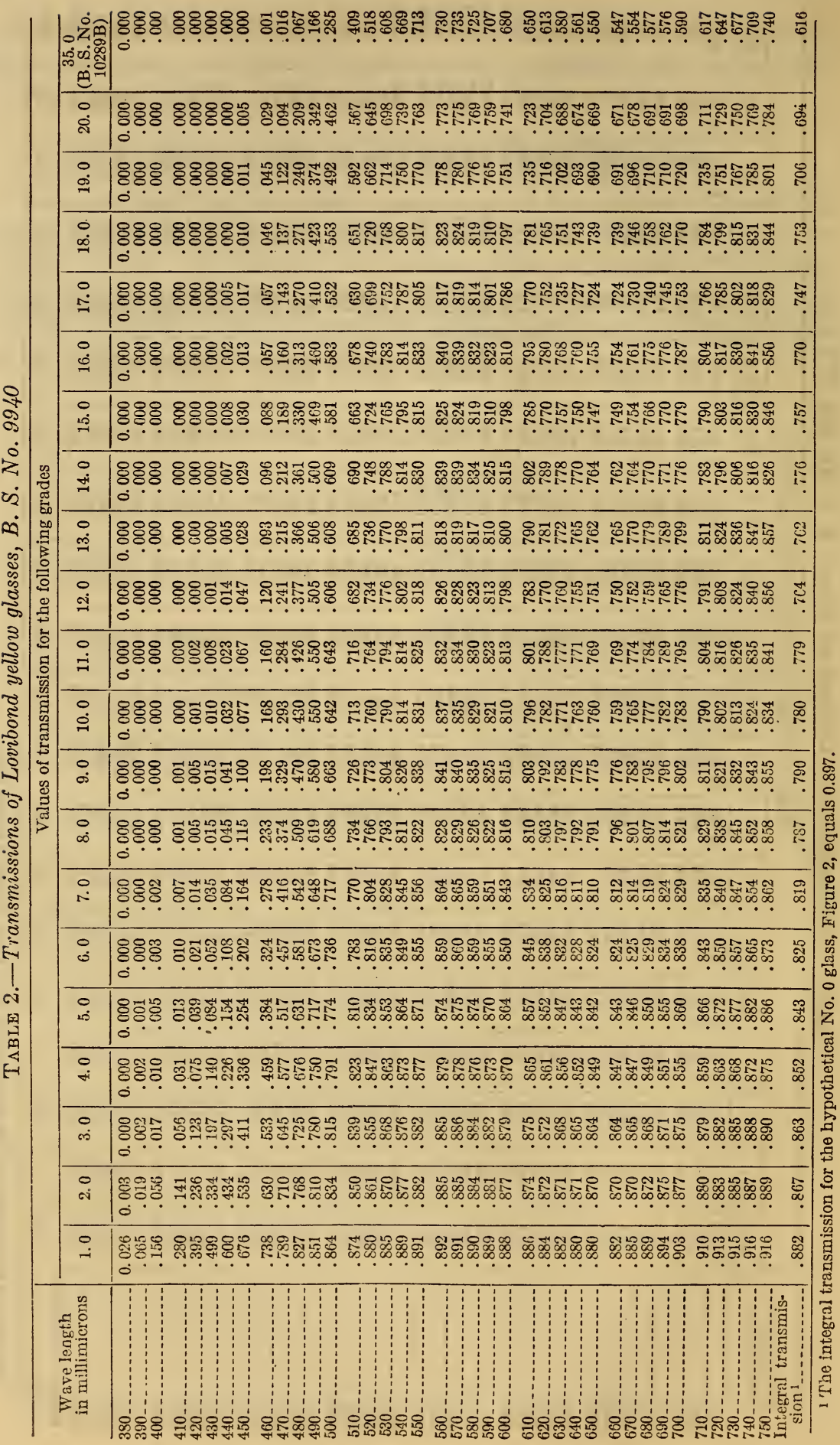




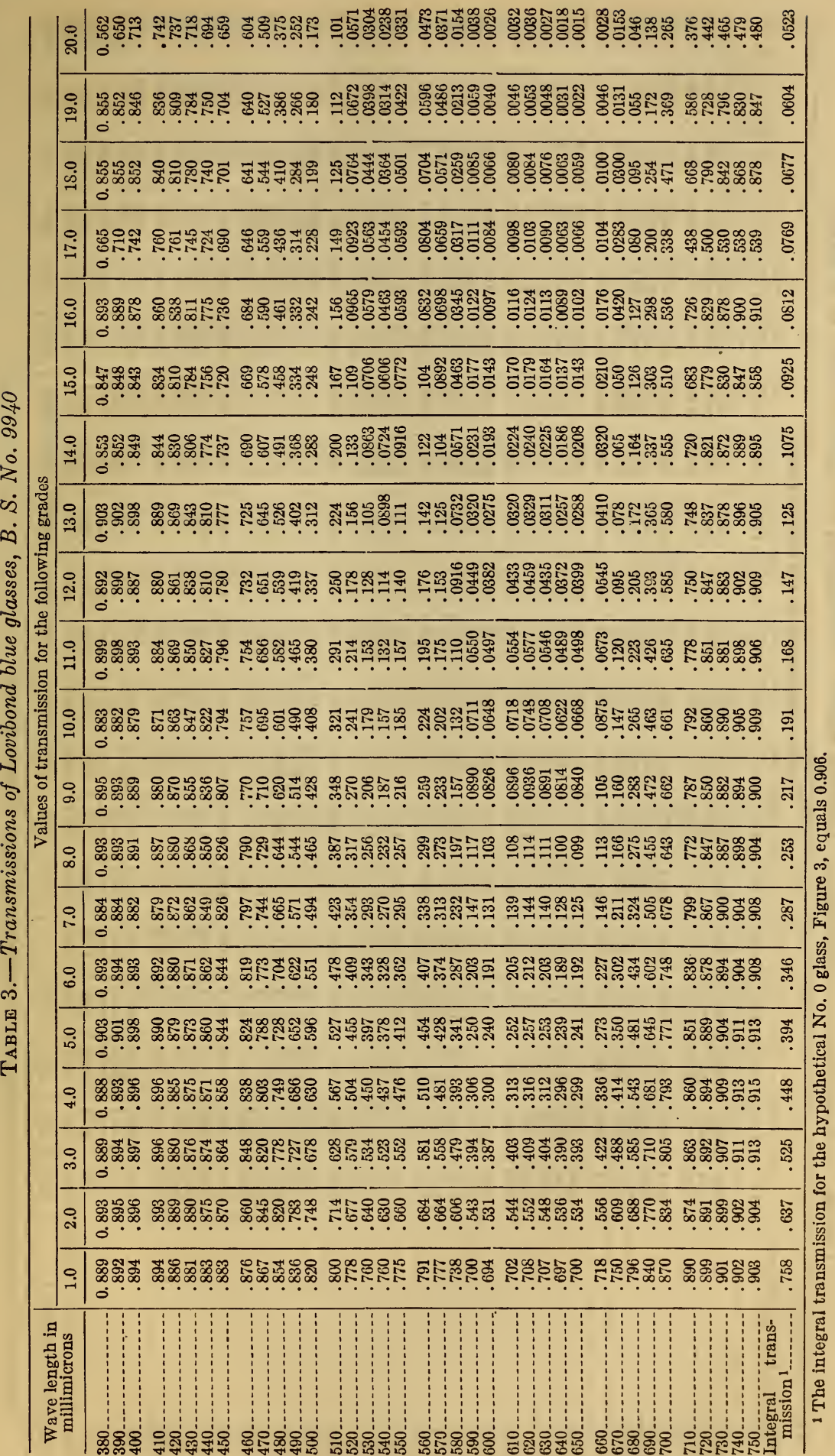




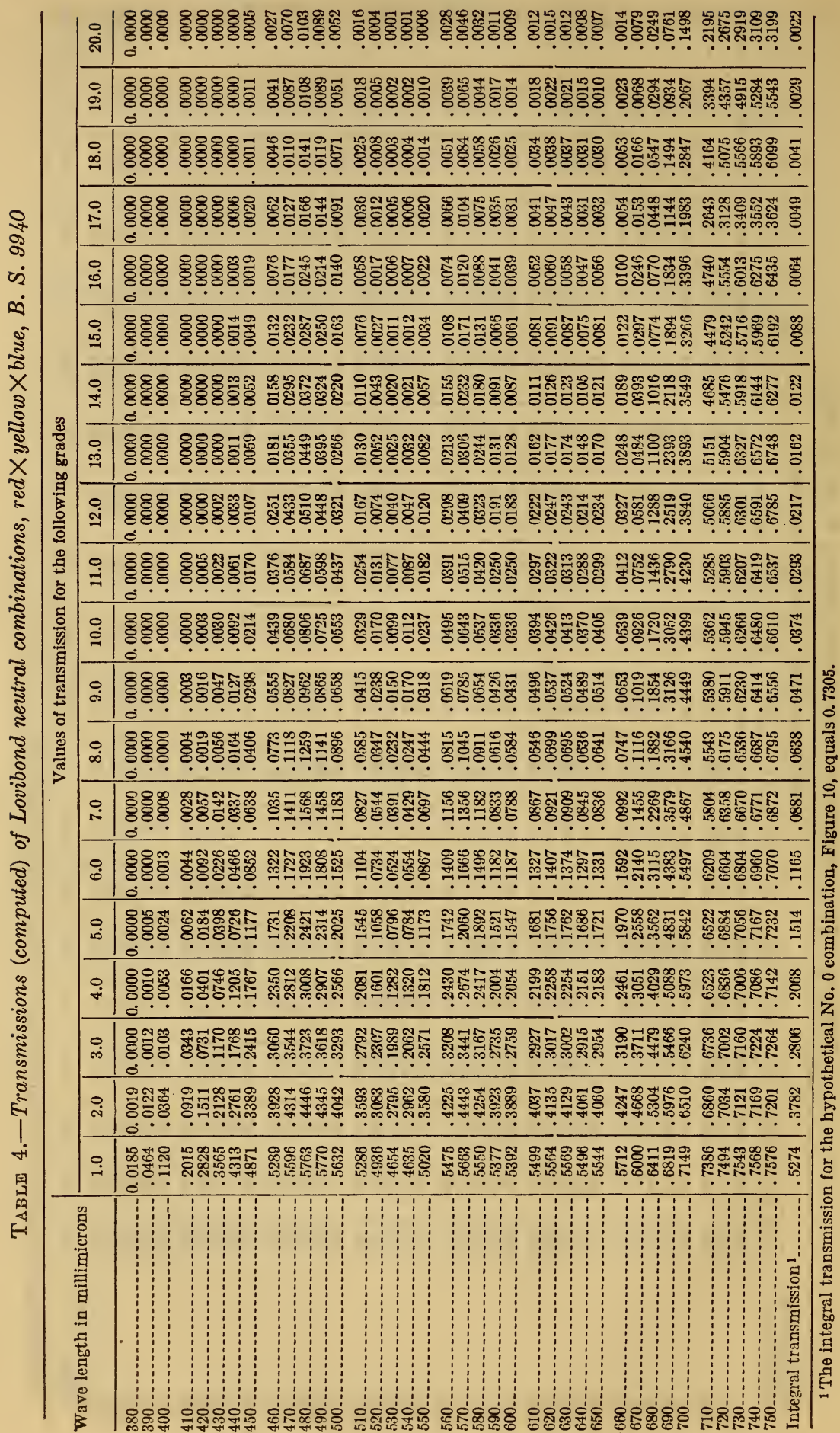




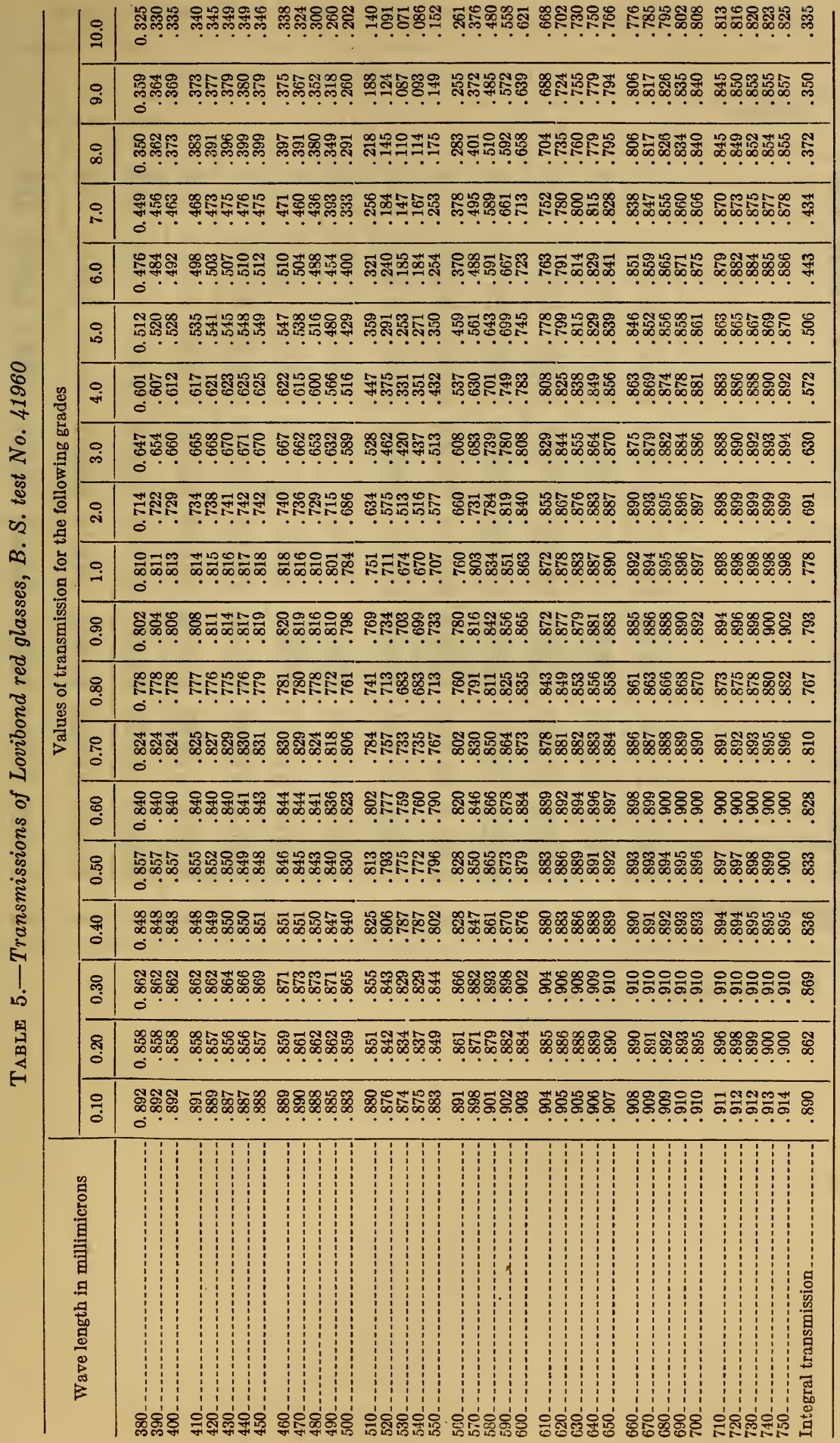


TABLE 6.-Transmissions of Lovibond yellow glasses, B. S. test No. 41960

\begin{tabular}{|c|c|c|c|c|c|c|c|c|c|c|c|c|c|}
\hline \multirow{2}{*}{$\begin{array}{l}\text { Wave length in } \\
\text { millimicrons }\end{array}$} & \multicolumn{13}{|c|}{ Values of transmission for the following grades } \\
\hline & 1.0 & 2.0 & 3.0 & 4.0 & 5.0 & 6. 0 & 7.0 & 8.0 & 9.0 & 10.0 & 20.0 & 30.0 & 35.0 \\
\hline $\begin{array}{l}380 \\
390 \\
400\end{array}$ & $\begin{array}{l}0.038 \\
.090 \\
.200\end{array}$ & $\begin{array}{r}0.000 \\
.010 \\
.040\end{array}$ & $\begin{array}{r}0.000 \\
.000 \\
.013\end{array}$ & $\begin{array}{r}0.000 \\
.000 \\
.001\end{array}$ & $\begin{array}{l}0.000 \\
.000 \\
.000\end{array}$ & $\begin{array}{r}0.000 \\
.000 \\
.000\end{array}$ & $\begin{array}{r}0.000 \\
.000 \\
.000\end{array}$ & $\begin{array}{l}0.000 \\
.000 \\
.000\end{array}$ & $\begin{array}{l}0.000 \\
.000 \\
.000\end{array}$ & $\begin{array}{r}0.000 \\
.000 \\
.000\end{array}$ & $\begin{array}{r}0.000 \\
.000 \\
.000\end{array}$ & $\begin{array}{r}0.000 \\
.000 \\
.000\end{array}$ & $\begin{array}{r}0.000 \\
.000 \\
.000\end{array}$ \\
\hline 440 & $\begin{array}{l}.320 \\
.431 \\
.530 \\
.616 \\
.690\end{array}$ & $\begin{array}{l}.124 \\
.223 \\
.324 \\
.425 \\
.528\end{array}$ & $\begin{array}{l}.051 \\
.114 \\
.193 \\
.298 \\
.403\end{array}$ & $\begin{array}{l}.017 \\
.051 \\
.109 \\
.192 \\
.311\end{array}$ & $\begin{array}{l}.011 \\
.033 \\
.078 \\
.150 \\
.256\end{array}$ & $\begin{array}{l}.004 \\
.014 \\
.042 \\
.097 \\
.185\end{array}$ & $\begin{array}{l}.000 \\
.005 \\
.022 \\
.067 \\
.149\end{array}$ & $\begin{array}{l}.001 \\
.010 \\
.030 \\
.075 \\
.151\end{array}$ & $\begin{array}{l}.000 \\
.000 \\
.006 \\
.026 \\
.087\end{array}$ & $\begin{array}{l}.000 \\
.000 \\
.007 \\
.029 \\
.079\end{array}$ & $\begin{array}{l}.000 \\
.000 \\
.000 \\
.000 \\
.003\end{array}$ & $\begin{array}{l}.000 \\
.000 \\
.000 \\
.000 \\
.000\end{array}$ & $\begin{array}{l}.000 \\
.000 \\
.000 \\
.000 \\
.000\end{array}$ \\
\hline $\begin{array}{l}480 \\
490 \\
500\end{array}$ & $\begin{array}{l}.747 \\
.788 \\
.815 \\
.830 \\
.842\end{array}$ & $\begin{array}{l}.629 \\
.715 \\
.771 \\
.810 \\
.833\end{array}$ & $\begin{array}{r}.511 \\
.616 \\
.698 \\
.755 \\
.791\end{array}$ & $\begin{array}{l}.442 \\
.568 \\
.666 \\
.736 \\
.779\end{array}$ & $\begin{array}{l}.397 \\
.535 \\
.646 \\
.728 \\
.781\end{array}$ & $\begin{array}{r}.305 \\
.438 \\
.559 \\
.656 \\
.721\end{array}$ & $\begin{array}{l}.280 \\
.426 \\
.552 \\
.649 \\
.717\end{array}$ & $\begin{array}{l}.262 \\
.398 \\
.517 \\
.620 \\
.689\end{array}$ & $\begin{array}{l}.202 \\
.351 \\
.490 \\
.609 \\
.692\end{array}$ & $\begin{array}{l}.175 \\
.305 \\
.440 \\
.557 \\
.650\end{array}$ & $\begin{array}{l}.025 \\
.088 \\
.199 \\
.329 \\
.451\end{array}$ & $\begin{array}{l}.005 \\
.030 \\
.100 \\
.220 \\
.355\end{array}$ & $\begin{array}{l}.003 \\
.022 \\
.081 \\
.187 \\
.313\end{array}$ \\
\hline & $\begin{array}{l}.850 \\
.855 \\
.859 \\
.862 \\
.865\end{array}$ & $\begin{array}{l}.846 \\
.856 \\
.863 \\
.868 \\
.872\end{array}$ & $\begin{array}{l}.816 \\
.835 \\
.847 \\
.855 \\
.860\end{array}$ & $\begin{array}{l}.805 \\
.824 \\
.835 \\
.843 \\
.849\end{array}$ & $\begin{array}{l}.817 \\
.840 \\
.855 \\
.865 \\
.871\end{array}$ & $\begin{array}{l}.770 \\
.803 \\
.825 \\
.837 \\
.845\end{array}$ & $\begin{array}{l}.764 \\
.792 \\
.811 \\
.825 \\
.833\end{array}$ & $\begin{array}{l}.735 \\
.766 \\
.793 \\
.811 \\
.822\end{array}$ & $\begin{array}{l}.753 \\
.792 \\
.818 \\
.836 \\
.847\end{array}$ & $\begin{array}{l}.719 \\
.761 \\
.790 \\
.815 \\
.829\end{array}$ & $\begin{array}{l}.555 \\
.633 \\
.685 \\
.722 \\
.747\end{array}$ & $\begin{array}{l}.481 \\
.577 \\
.650 \\
.704 \\
.738\end{array}$ & $\begin{array}{l}.434 \\
.540 \\
.623 \\
.682 \\
.720\end{array}$ \\
\hline & $\begin{array}{l}.867 \\
.868 \\
.868 \\
.868 \\
.868\end{array}$ & $\begin{array}{l}.874 \\
.875 \\
.875 \\
.874 \\
.873\end{array}$ & $\begin{array}{l}.863 \\
.864 \\
.863 \\
.861 \\
.859\end{array}$ & $\begin{array}{l}.853 \\
.855 \\
.857 \\
.858 \\
.857\end{array}$ & $\begin{array}{l}.875 \\
.875 \\
.873 \\
.870 \\
.866\end{array}$ & $\begin{array}{l}.849 \\
.849 \\
.846 \\
.842 \\
.835\end{array}$ & $\begin{array}{l}.836 \\
.837 \\
.835 \\
.831 \\
.825\end{array}$ & $\begin{array}{l}.826 \\
.828 \\
.826 \\
.823 \\
.819\end{array}$ & $\begin{array}{l}.853 \\
.854 \\
.853 \\
.849 \\
.844\end{array}$ & $\begin{array}{l}.835 \\
.835 \\
.833 \\
.826 \\
.817\end{array}$ & $\begin{array}{l}.760 \\
.762 \\
.755 \\
.745 \\
.730\end{array}$ & $\begin{array}{l}.752 \\
.753 \\
.744 \\
.726 \\
.703\end{array}$ & $\begin{array}{l}.738 \\
.742 \\
.735 \\
.719 \\
.698\end{array}$ \\
\hline $650-1$ & $\begin{array}{l}.867 \\
.866 \\
.866 \\
.866 \\
.866\end{array}$ & $\begin{array}{l}.872 \\
.871 \\
.870 \\
.870 \\
.870\end{array}$ & $\begin{array}{l}.857 \\
.855 \\
.855 \\
.855 \\
.856\end{array}$ & $\begin{array}{l}.855 \\
.853 \\
.851 \\
.850 \\
.850\end{array}$ & $\begin{array}{l}.863 \\
.860 \\
.859 \\
.858 \\
.857\end{array}$ & $\begin{array}{l}.826 \\
.820 \\
.812 \\
.805 \\
.803\end{array}$ & $\begin{array}{l}.820 \\
.815 \\
.811 \\
.807 \\
.805\end{array}$ & $\begin{array}{l}.815 \\
.811 \\
.808 \\
.805 \\
.805\end{array}$ & $\begin{array}{l}.836 \\
.829 \\
.822 \\
.814 \\
.807\end{array}$ & $\begin{array}{l}.805 \\
.794 \\
.785 \\
.780 \\
.778\end{array}$ & $\begin{array}{l}.712 \\
.695 \\
.679 \\
.668 \\
.663\end{array}$ & $\begin{array}{l}.675 \\
.650 \\
.629 \\
.613 \\
.604\end{array}$ & $\begin{array}{l}.671 \\
.645 \\
.620 \\
.602 \\
.591\end{array}$ \\
\hline 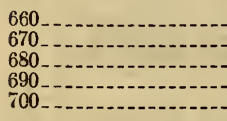 & $\begin{array}{l}.866 \\
.867 \\
.869 \\
.8874\end{array}$ & $\begin{array}{l}.872 \\
.874 \\
.876 \\
.879 \\
.881\end{array}$ & $\begin{array}{l}.858 \\
.861 \\
.864 \\
.867 \\
.870\end{array}$ & $\begin{array}{l}.852 \\
.855 \\
.859 \\
.863 \\
.866\end{array}$ & $\begin{array}{l}.858 \\
.860 \\
.862 \\
.865 \\
.867\end{array}$ & $\begin{array}{l}.803 \\
.805 \\
.809 \\
.814 \\
.819\end{array}$ & $\begin{array}{l}.806 \\
.809 \\
.813 \\
.818 \\
.823\end{array}$ & $\begin{array}{l}.807 \\
.811 \\
.816 \\
.821 \\
.826\end{array}$ & $\begin{array}{l}.806 \\
.813 \\
.825 \\
.826 \\
.830\end{array}$ & $\begin{array}{l}.780 \\
.786 \\
.795 \\
.795 \\
.799\end{array}$ & $\begin{array}{l}.663 \\
.671 \\
.682 \\
.686 \\
.703\end{array}$ & $\begin{array}{l}.605 \\
.614 \\
.629 \\
.628 \\
.642\end{array}$ & $\begin{array}{l}.590 \\
.599 \\
.611 \\
.617 \\
.629\end{array}$ \\
\hline $\begin{array}{l}710 \\
720 \\
730 \\
740\end{array}$ & $\begin{array}{l}.876 \\
.879 \\
.882 \\
.884 \\
.888\end{array}$ & $\begin{array}{l}.884 \\
.886 \\
.889 \\
.892 \\
.895\end{array}$ & $\begin{array}{l}.873 \\
.876 \\
.880 \\
.883 \\
.886\end{array}$ & $\begin{array}{l}.870 \\
.874 \\
.877 \\
.880 \\
.883\end{array}$ & $\begin{array}{l}.870 \\
.873 \\
.876 \\
.880 \\
.883\end{array}$ & $\begin{array}{l}.825 \\
.831 \\
.837 \\
.845 \\
.852\end{array}$ & $\begin{array}{l}.829 \\
.835 \\
.841 \\
.848 \\
.854\end{array}$ & $\begin{array}{l}.833 \\
.839 \\
.846 \\
.852 \\
.857\end{array}$ & $\begin{array}{l}.836 \\
.844 \\
.852 \\
.861 \\
.871\end{array}$ & $\begin{array}{l}.808 \\
.820 \\
.830 \\
.841 \\
.852\end{array}$ & $\begin{array}{l}.722 \\
.744 \\
.765 \\
.787 \\
.810\end{array}$ & $\begin{array}{l}.665 \\
.693 \\
.728 \\
.767 \\
.810\end{array}$ & $\begin{array}{r}.650 \\
.678 \\
.710 \\
.743 \\
.778\end{array}$ \\
\hline $\begin{array}{l}\text { Integral transmis- } \\
\text { sion }\end{array}$ & .860 & .861 & .842 & .832 & .846 & .812 & .801 & .788 & .809 & .783 & .681 & .650 & .632 \\
\hline
\end{tabular}

Washington, May 20, 1926. 


\section{GRAPHS}




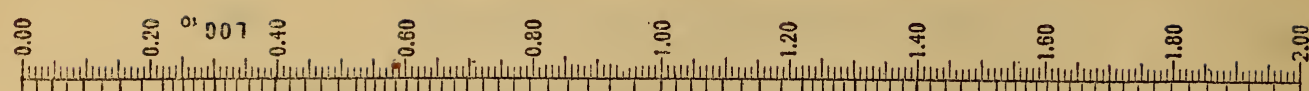

\begin{tabular}{|l|l|l|}
\hline \\
\hline
\end{tabular}

H. Wh

- win

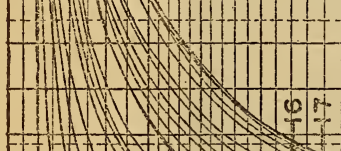

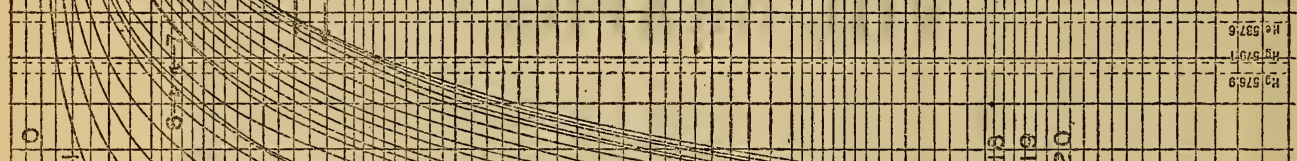
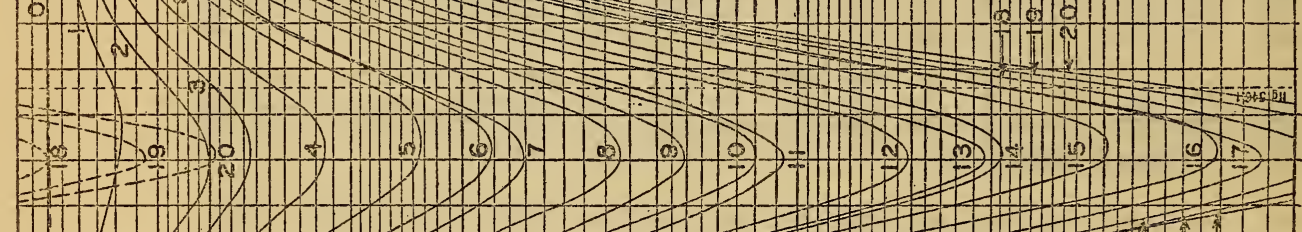

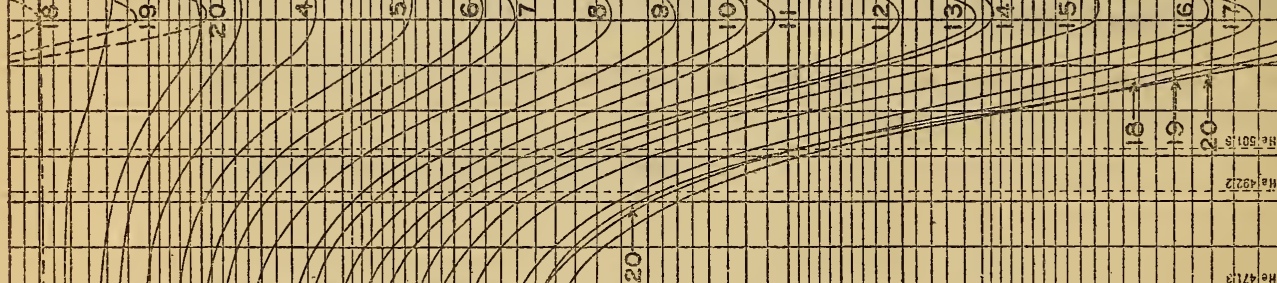

-

5 -

-

Sii

H.

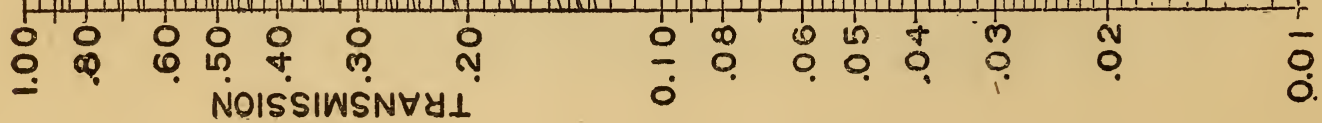

$\sum_{\substack{10 \\ 0}}^{T}$

$\begin{array}{llll}0 & 0 & 0 \\ 0 & 0 & 0 & 0 \\ 0 & 0 & 0 & 0 \\ 0\end{array}$

$\sum_{1}$

ธิ :

है

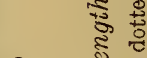

요

10 每

(1) वे व

త్

0 帘合

$0 \quad 0$

83

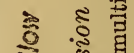

동

हूँ

० इँ

$10 \mathrm{f}$ है

L 8

के के

एं

क की

0 .

(1) ङ

उ

हี

๑) :

०बे है ज़

।

-i 댕ㅈ

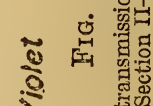

0 ัั

总 


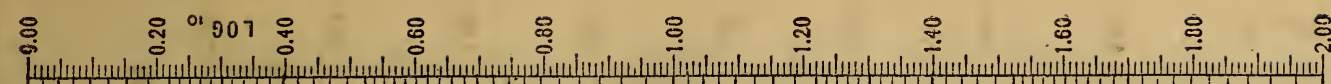

Imلس

|

(n)

m.1.

HWh-t

\begin{tabular}{|c|}
\hline \\
\hline \\
\hline
\end{tabular}

(1)

(1)

W.

14 W

$=$

AX

in

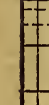

.

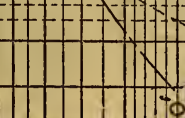

.

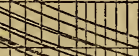




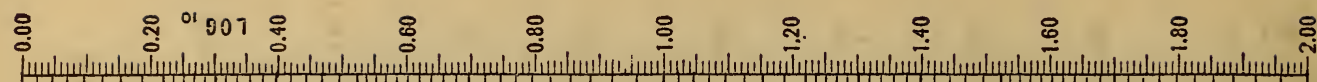

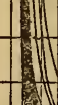

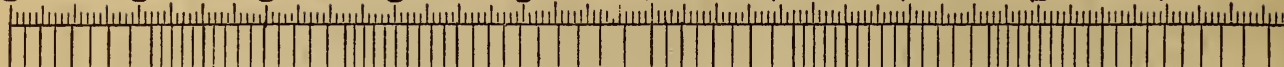

(1)

EN $\sqrt{2}$

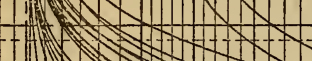

$11 \times 1$

$1=7=-1 .+1-1+1$

IIF-E

of 1 -

1)-

1.1

की

$E^{2}=-x^{2}$

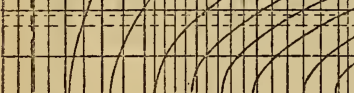

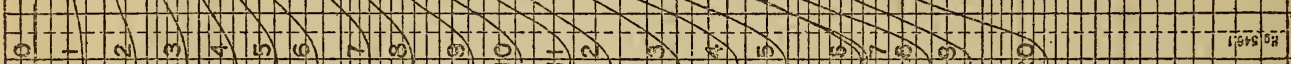

$$
\text { |- }
$$ \\ =

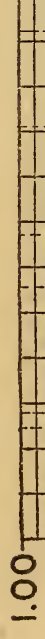

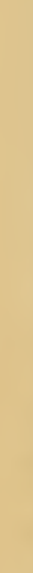
$=\sqrt{5}$ $1 N$

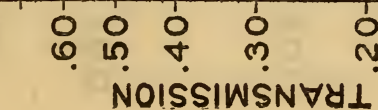

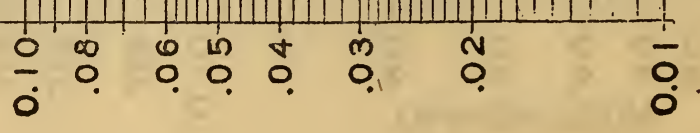




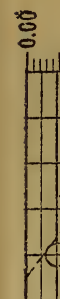

ลุ. ำ 907

:

$\stackrel{8}{\circ}$

용 \&

:

क्रो

10 6 of

H

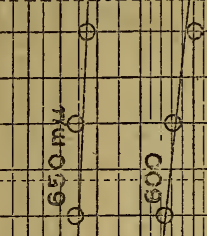

-

6

91
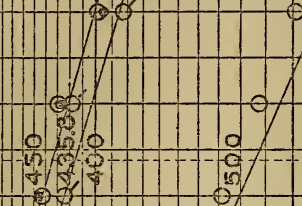

a
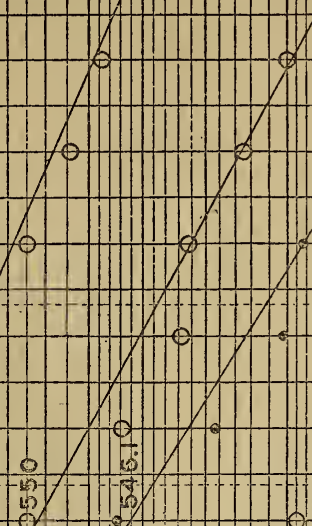

$1+1$
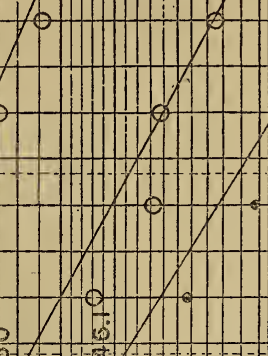

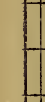

d 9

$+1003$

$6(11110$

$+60$

118

की 1

$\rightarrow$ (1)
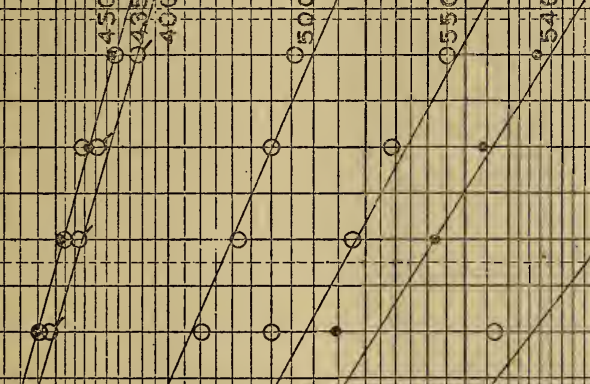

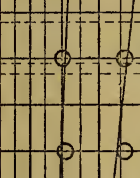
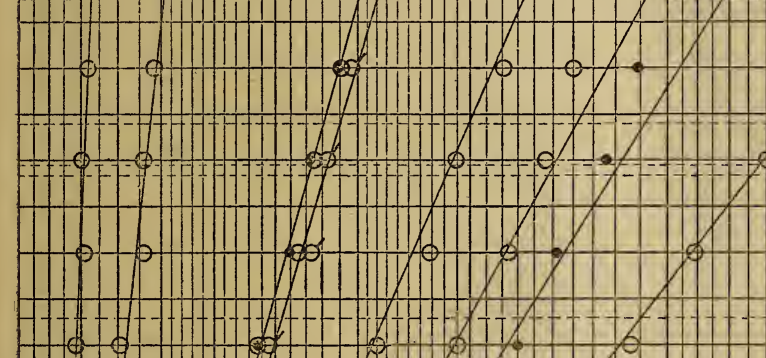

$H$

-1n-
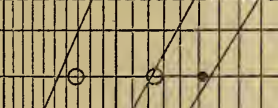

$=$

16 0 a

-o - $-=0$ - 0 - 0.10

$01-0$

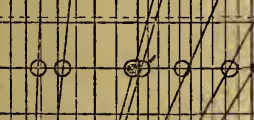

-

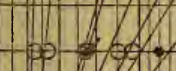

.

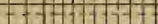

178

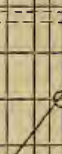




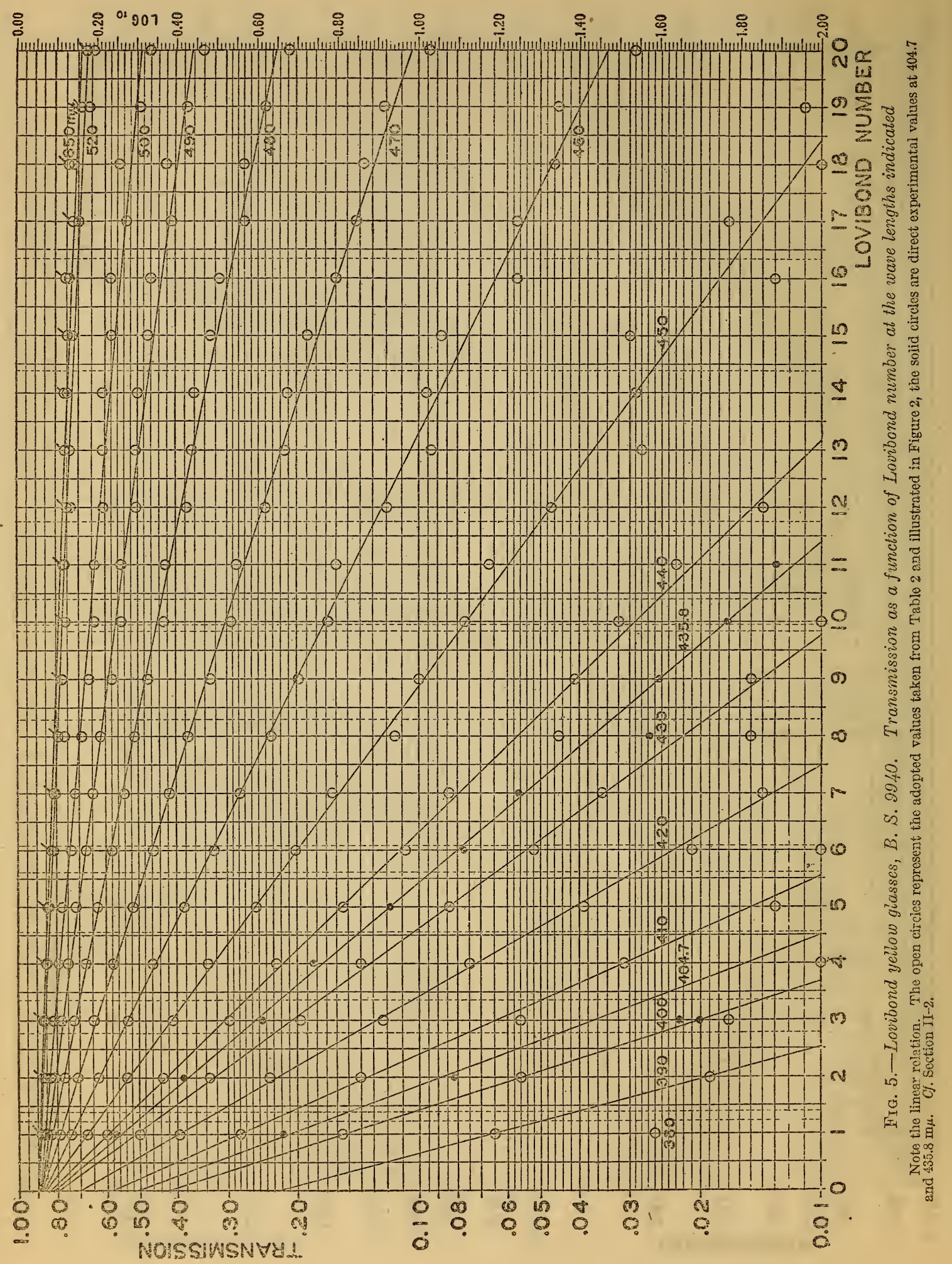




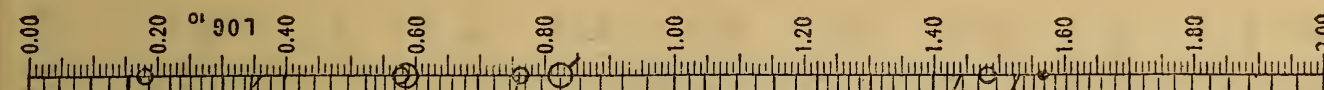

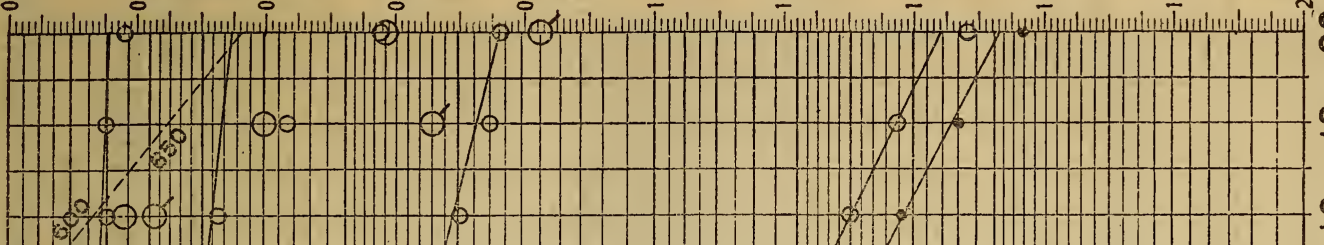 \\ 10. bo in in
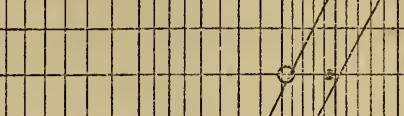

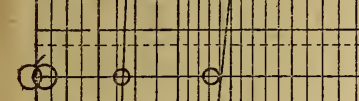

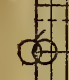

H-

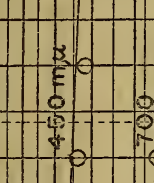

$+$

:
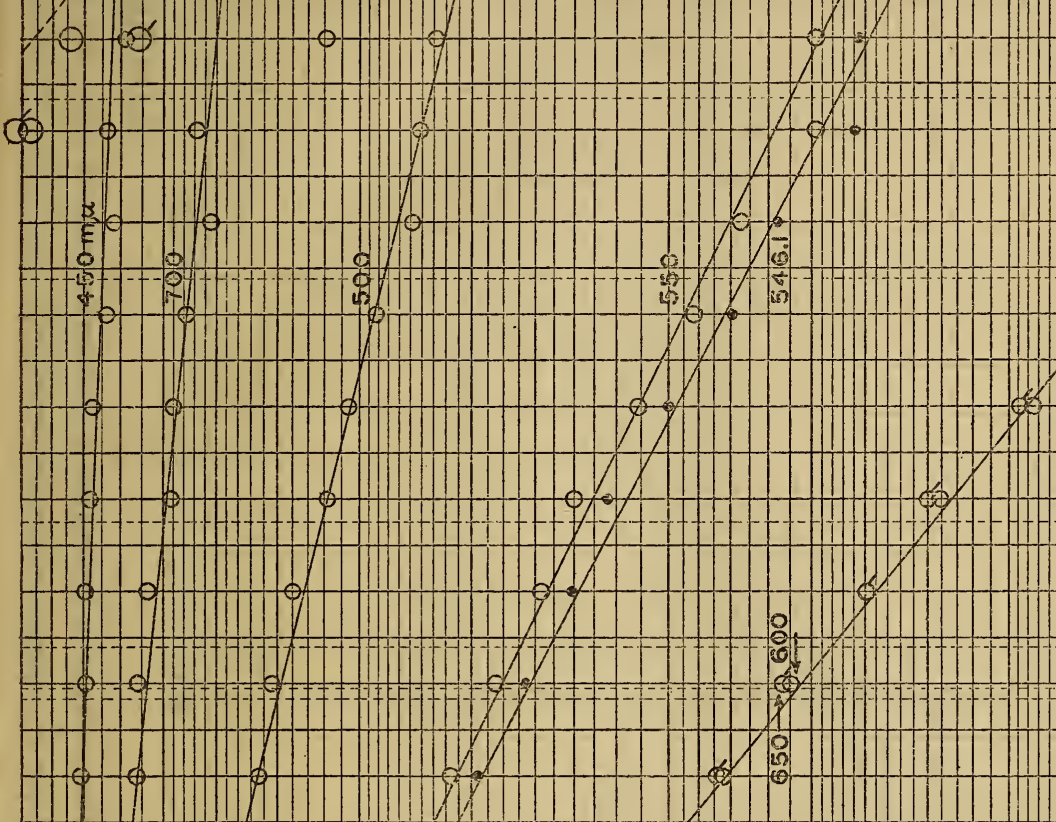

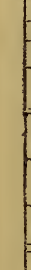
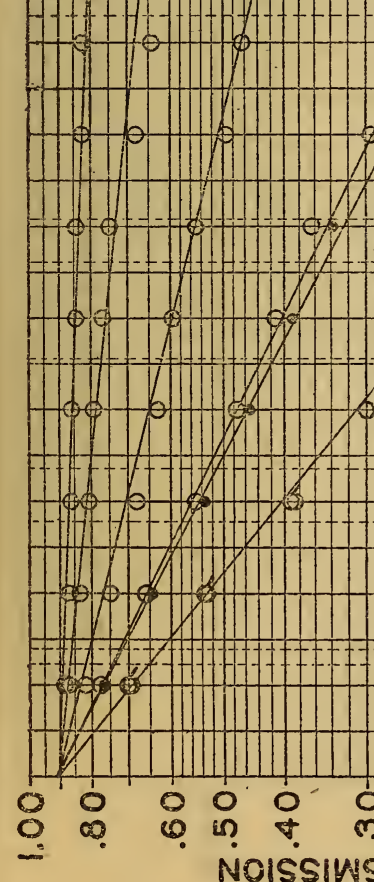

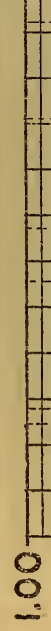
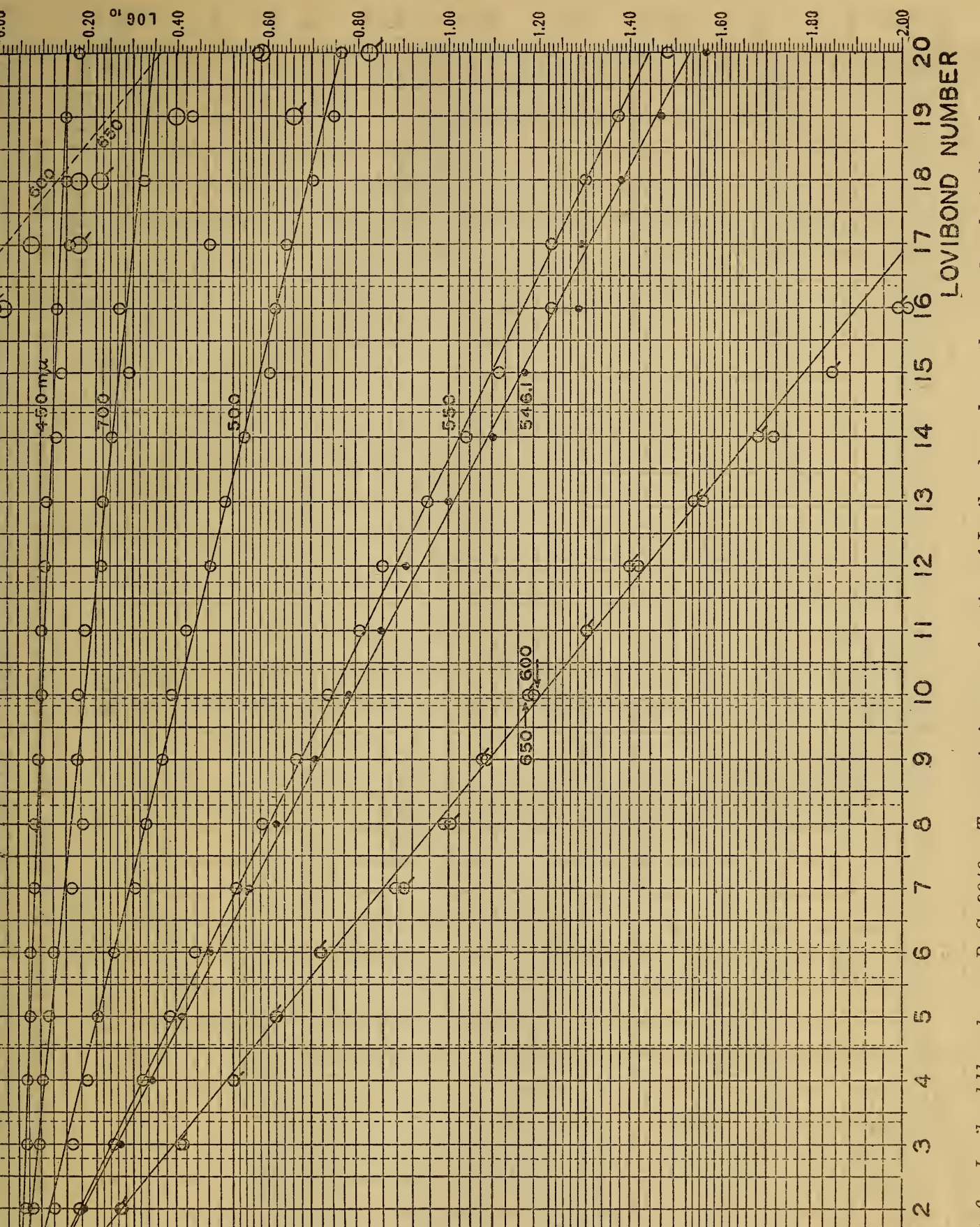

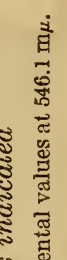

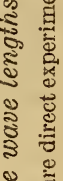

(ะ)

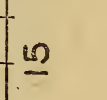

के

ฐँ

$+\quad$ 弯

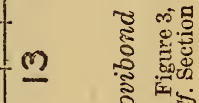

N 40.

N 2

$=$ =

$0 \quad 0$ 每

음

$\infty$
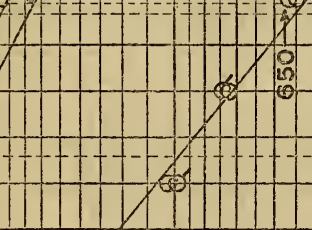

के हू.

.

\%

है

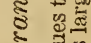

स-

○.

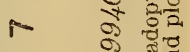

is

ir.

$\infty$

की

赵

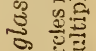

\&

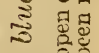

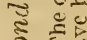

要

害

T

0.0

ن

昰

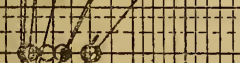

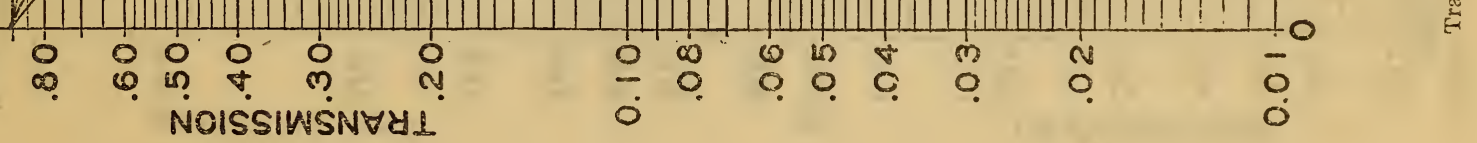


\& $\stackrel{0}{0} 007$ 웅

1

$1+\mid-1010$ t7ff-fint 1

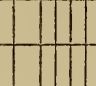

H-t

111 $7-$
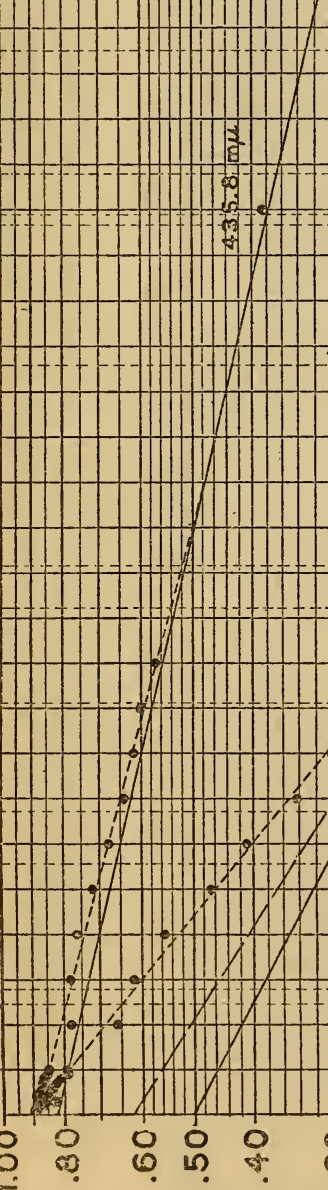

@
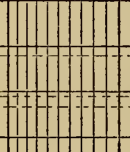

11

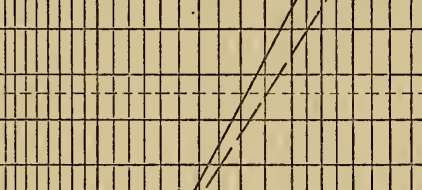

$$
+1+
$$




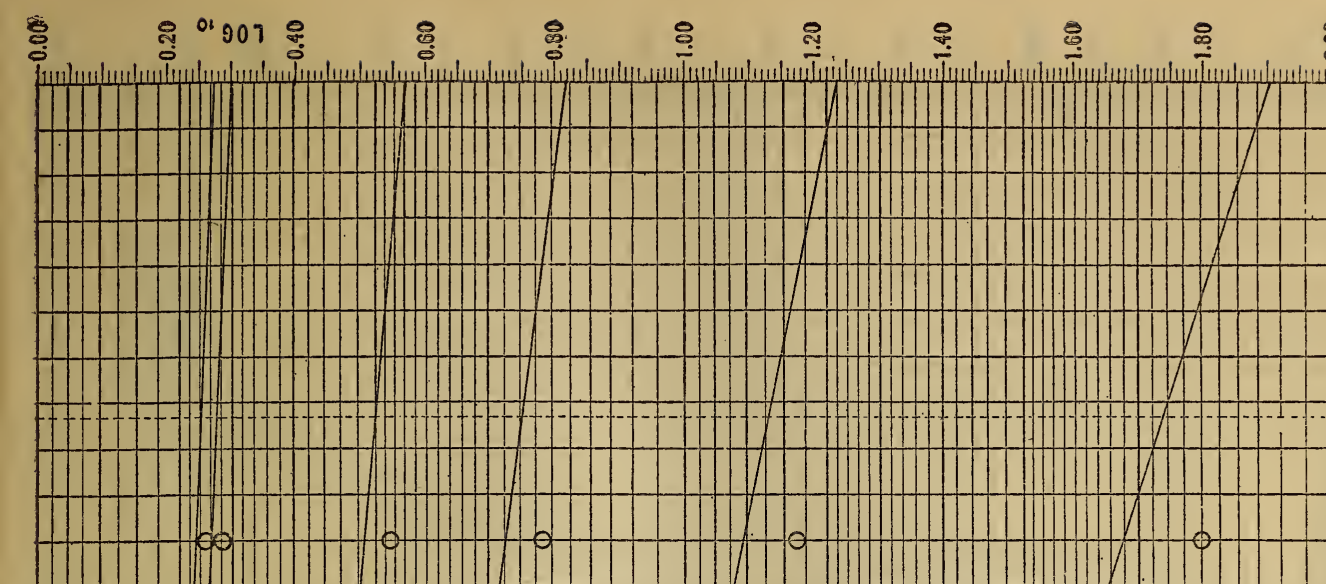

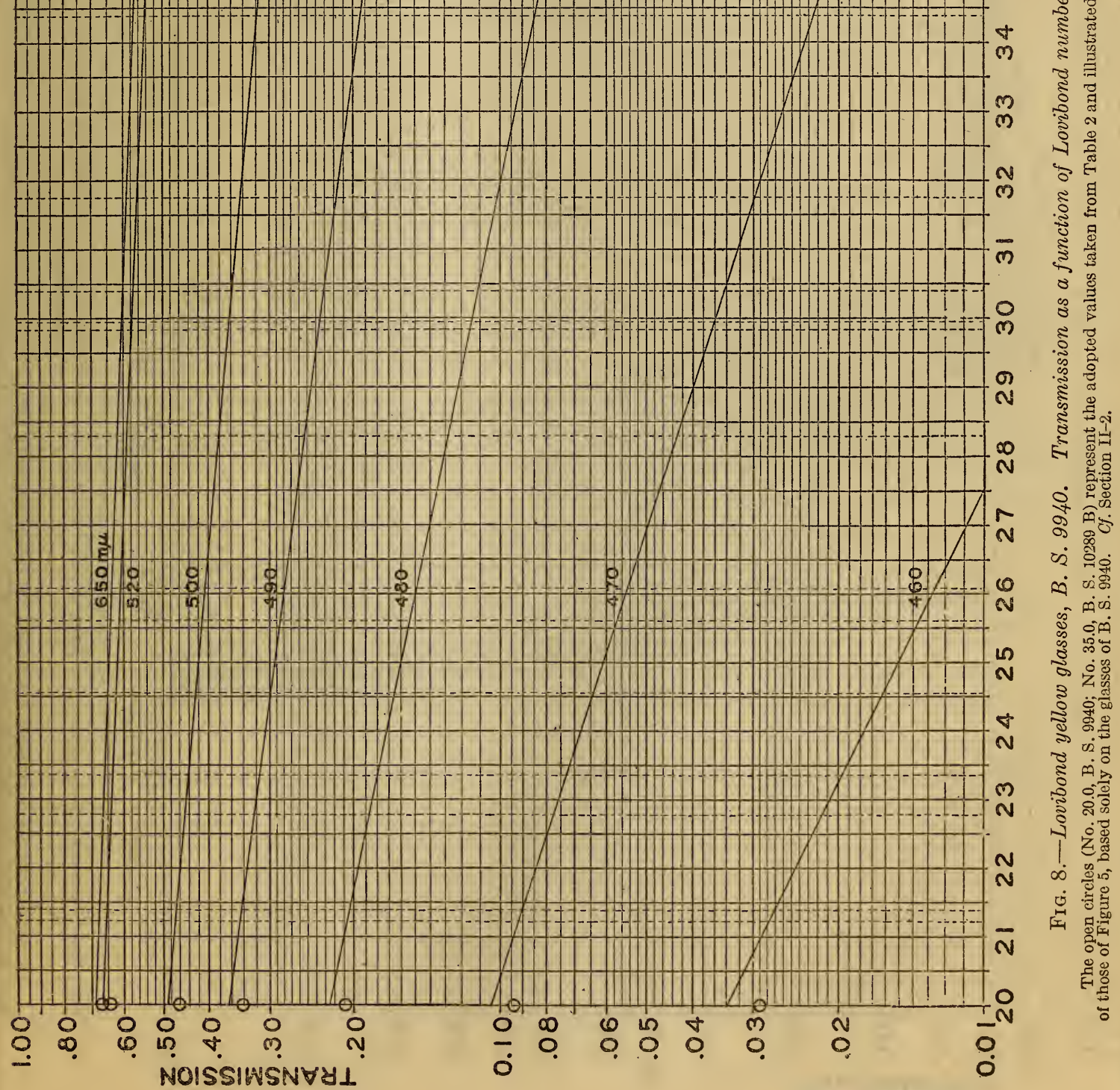




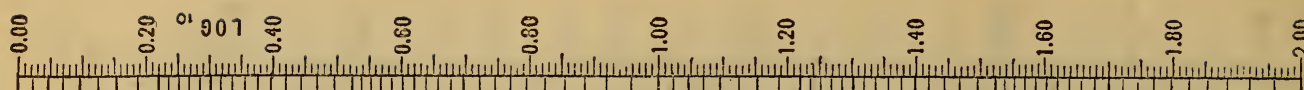

Im

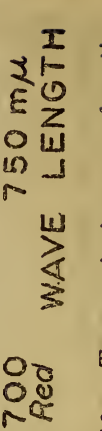

\begin{tabular}{|r|l|l|l|}
\hline & \\
\hline
\end{tabular}

H.
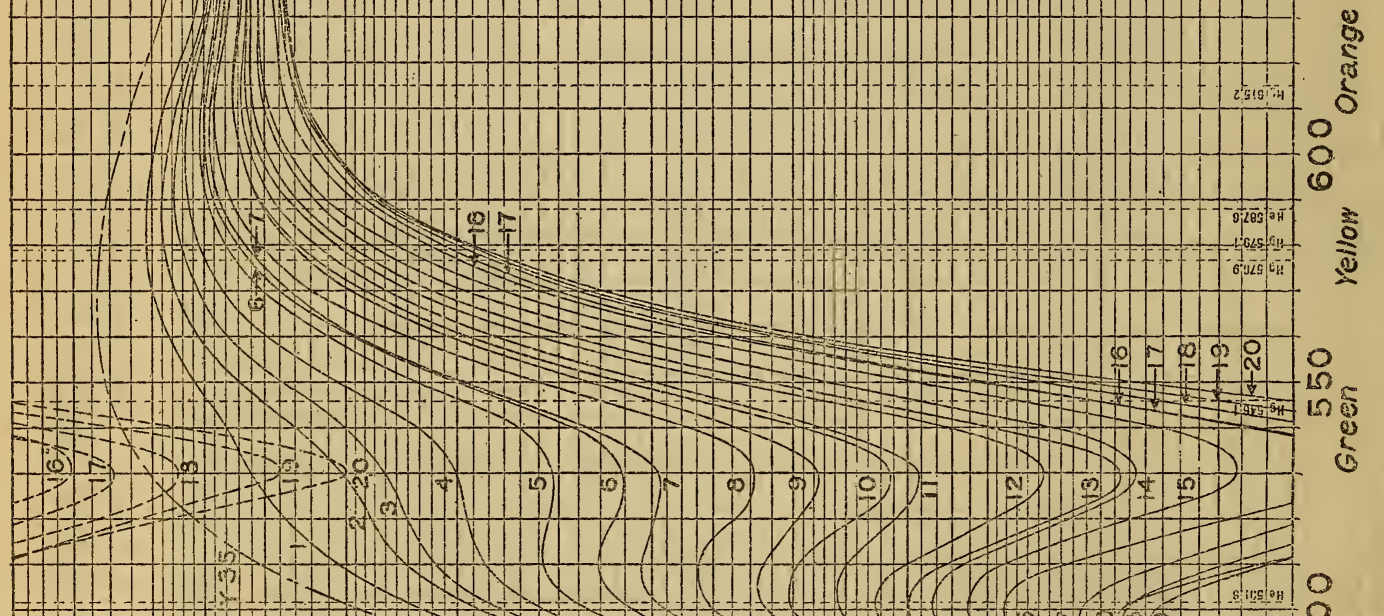

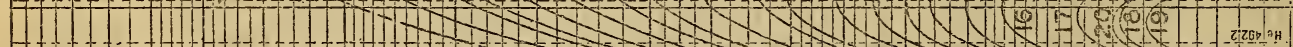

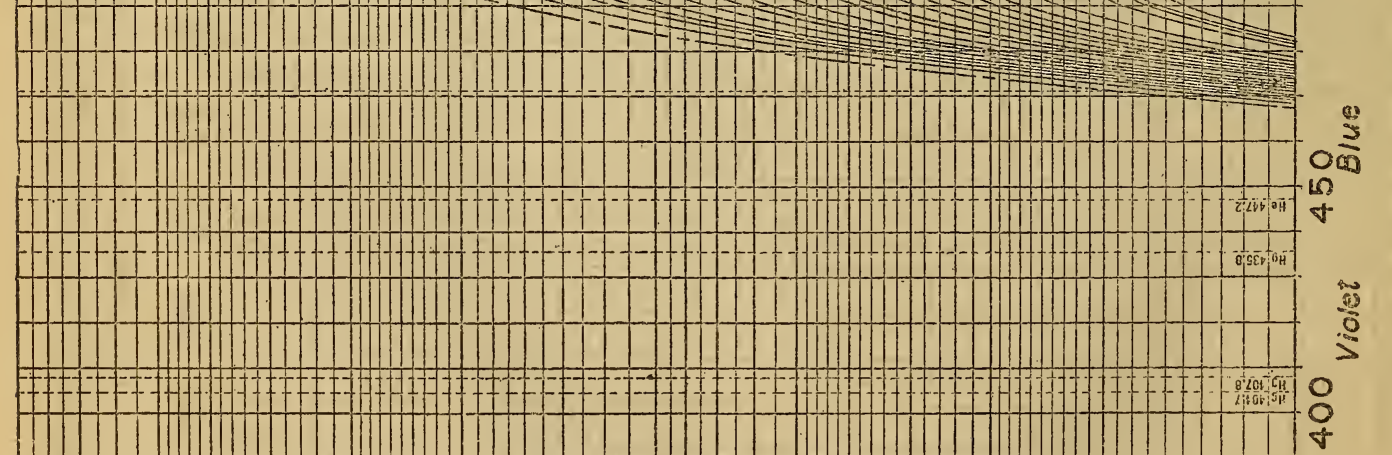

10

동ㅁㅇㅇ

范

苛官

유메

焉

\&ू

औ 
ஃ.

"या

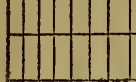

H I (

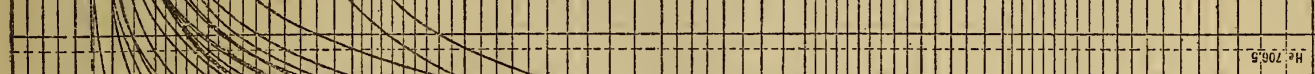

$17+1.1 x$

$1+1 \times-7$

$21 \mathrm{~N} N \mathrm{~N} \times$

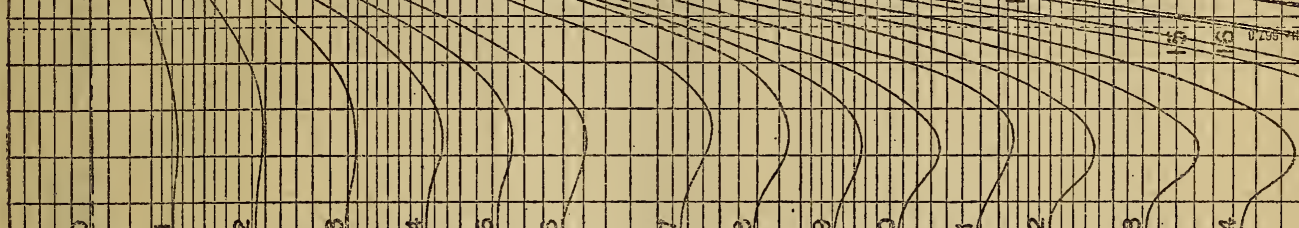

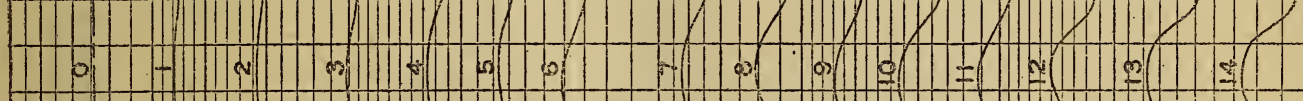

H-H-

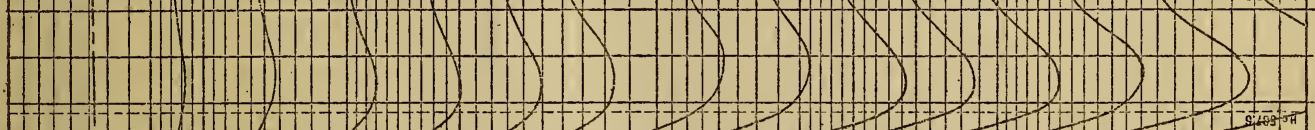

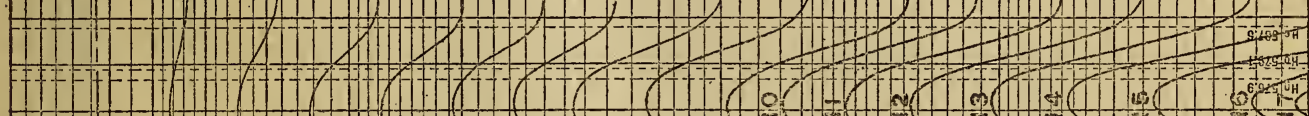

17 N N N N N N

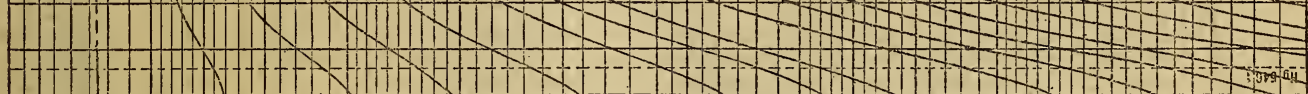

1.

(1) 111100 की

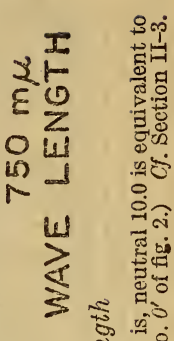

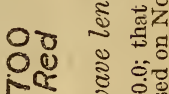

-

is 용

₹

ज्ञ

焉得

$\begin{array}{lll}0 & 5 \\ 1 & 0 & 0 \\ 0 & 0\end{array}$

0 巳 ह

ก \%

0.

है ङ

ठ हैं है

0 है क्षे०

0 담

के के

के

1) के क्षे

व

- के है

以ธ

(1)

ठิ

हैं

1 . 1 (1)

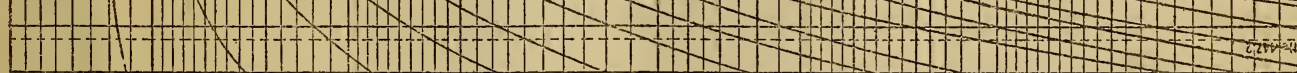

-

11 W.

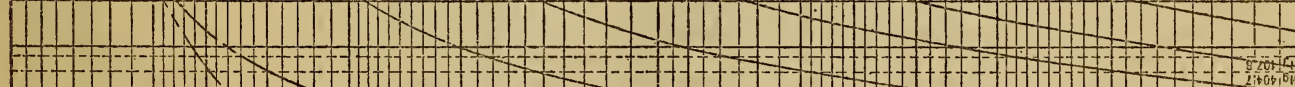

I

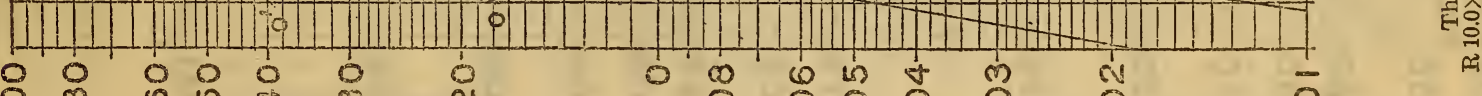




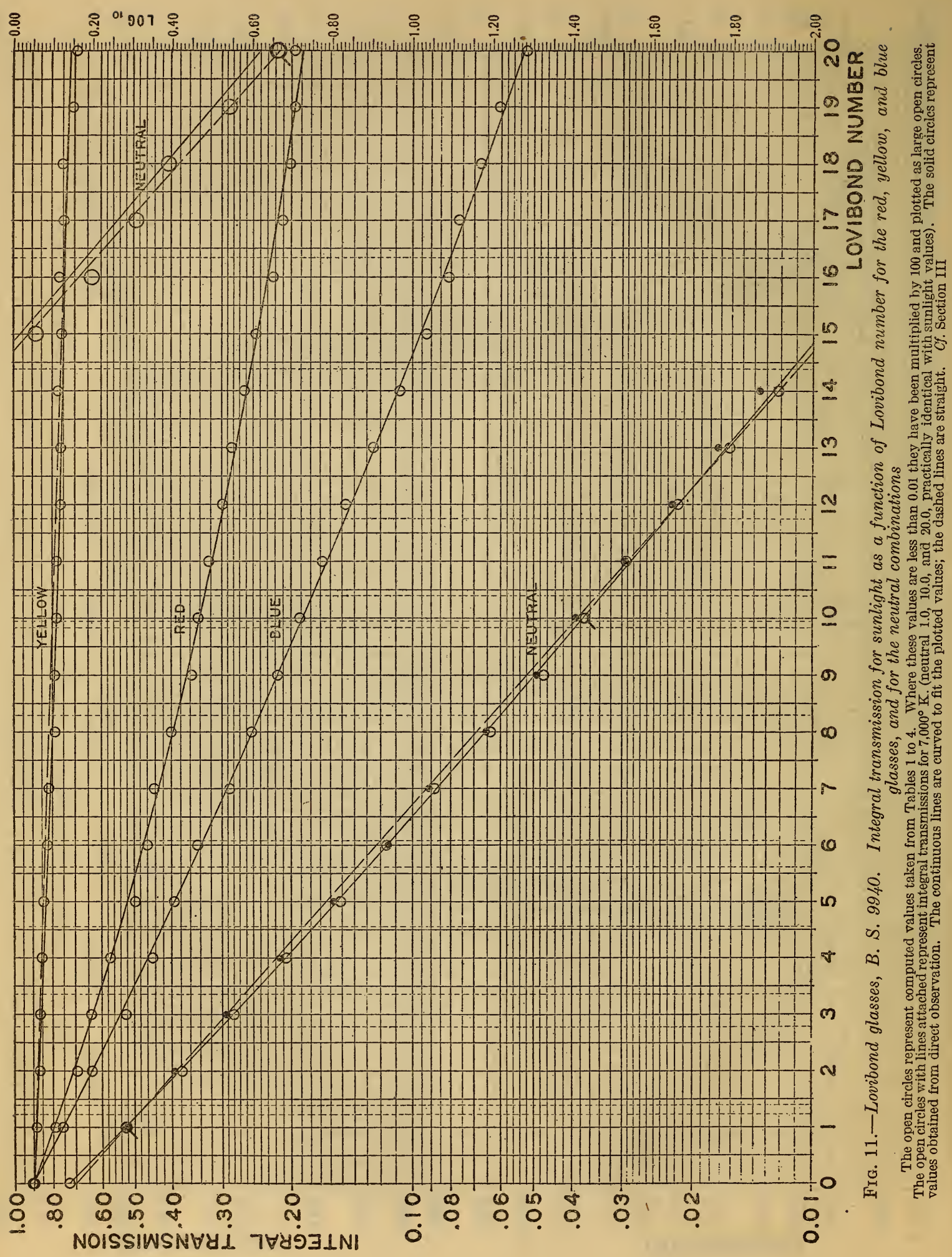




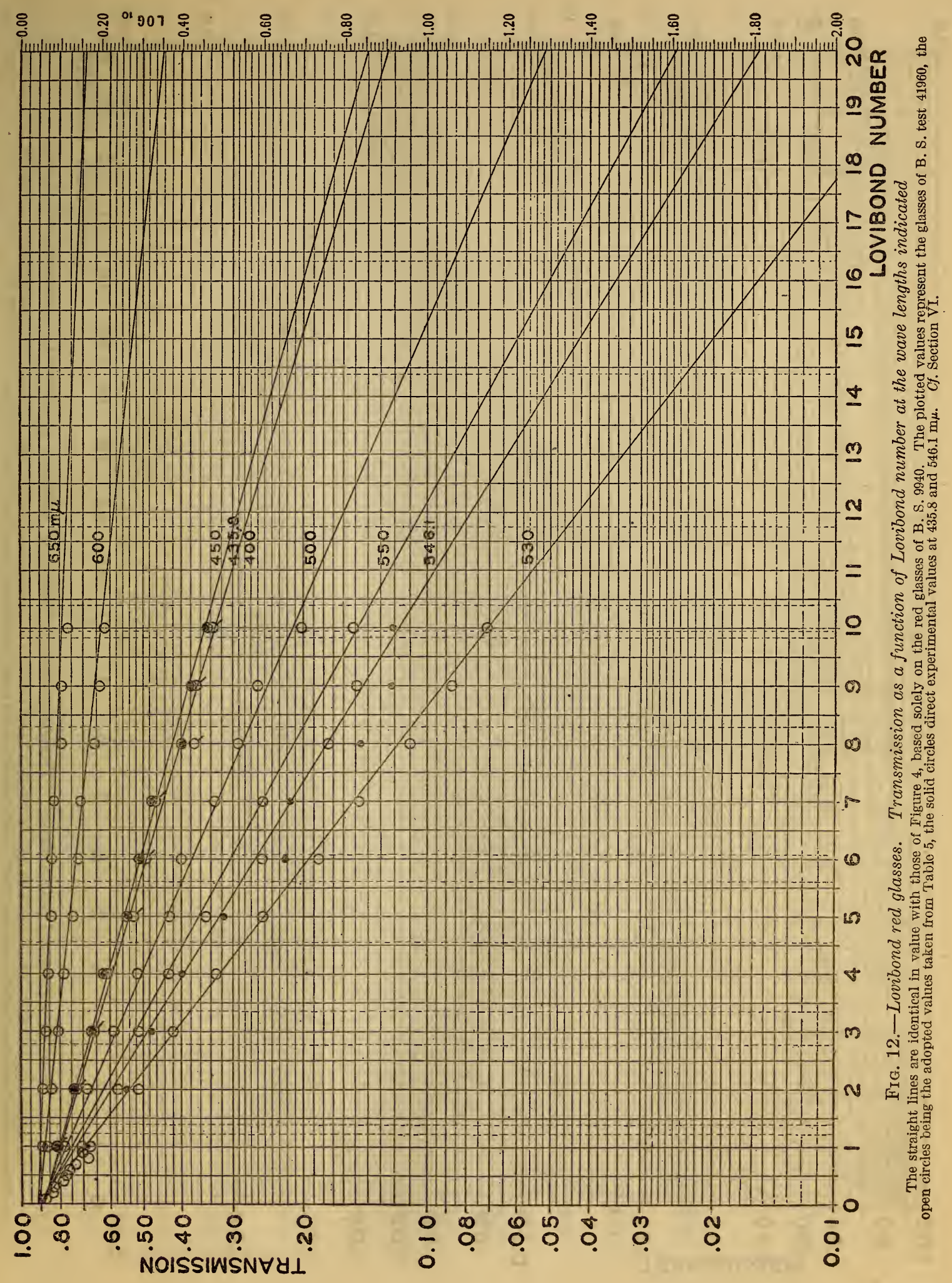


¿.

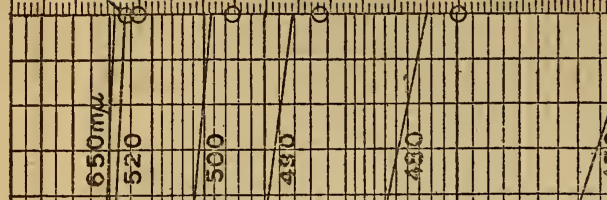

\begin{tabular}{|l|} 
\\
\hline
\end{tabular}

(1)

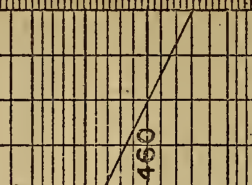

구응

$\rightarrow+0$

11

$1+1 \mid$

Y||
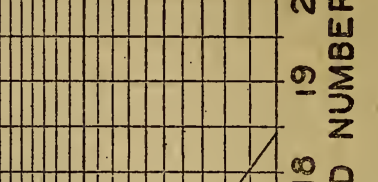

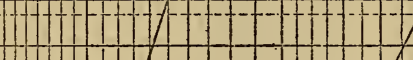

t

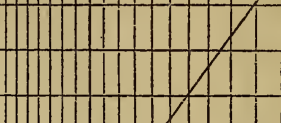

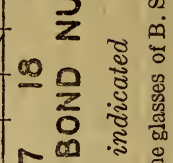

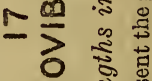

$\infty$

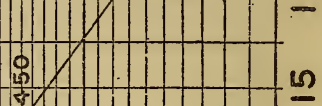

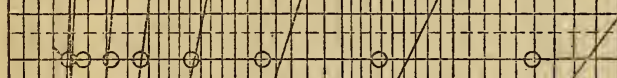

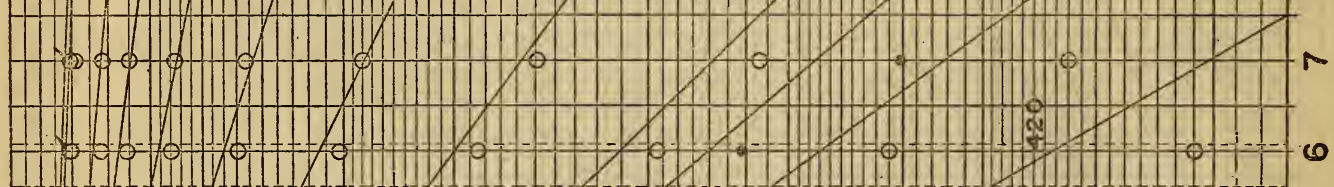

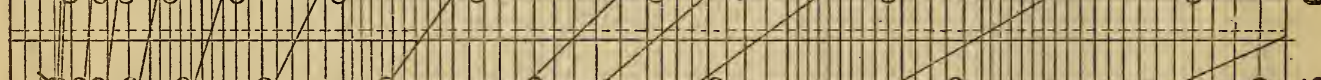

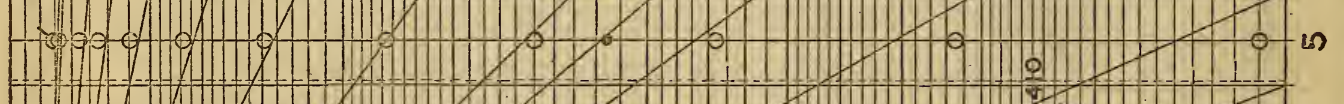
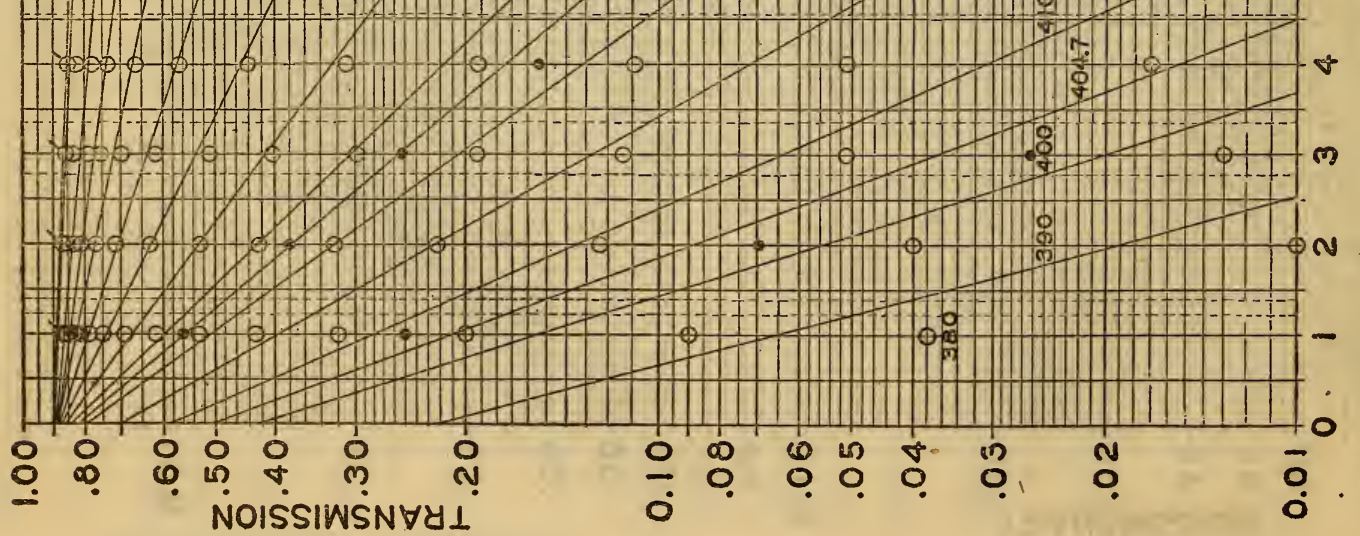


\section{$\underset{\text { Priest }}{\text { Gibson, Harris, }]}$

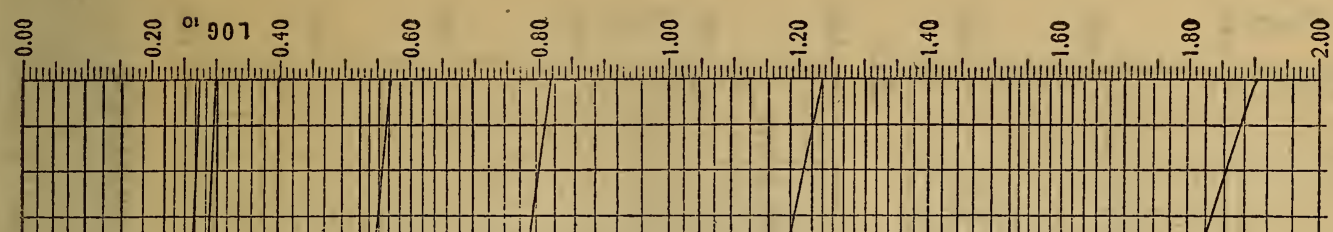

\begin{tabular}{|c|}
\hline \\
\hline 0
\end{tabular}

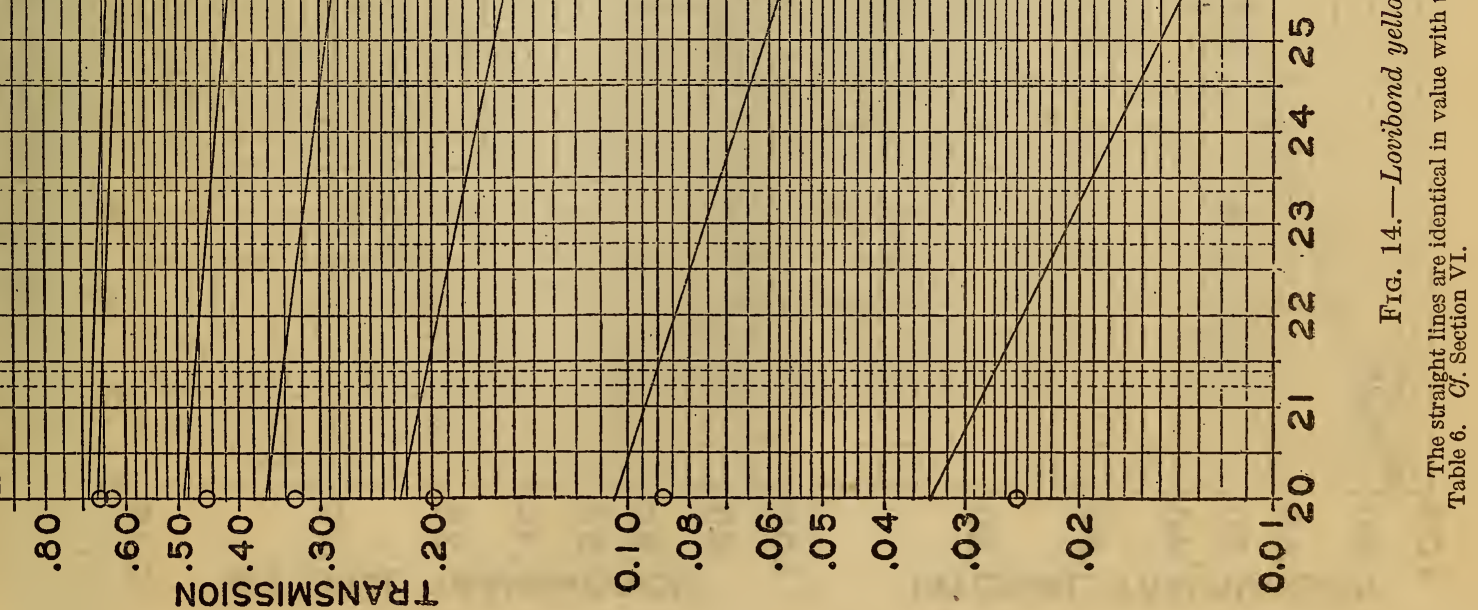

s

हี้ ฝี

ริ नี

T

을

至

țī 

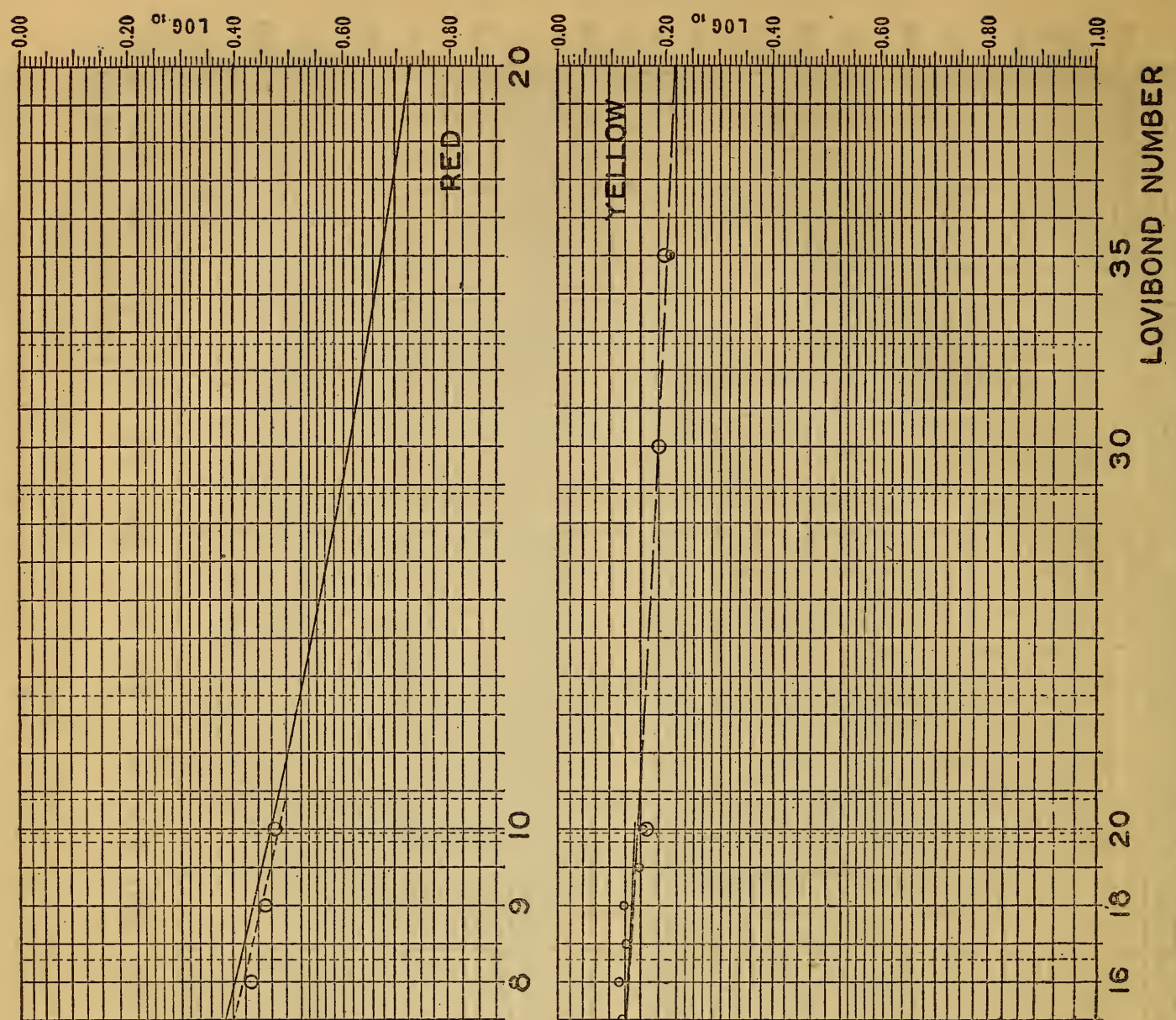

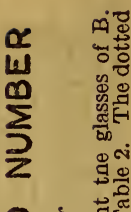

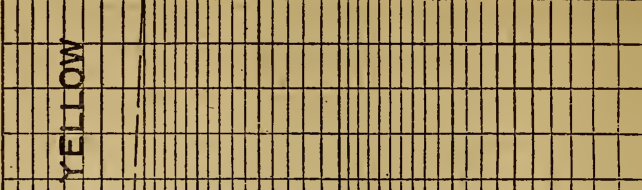

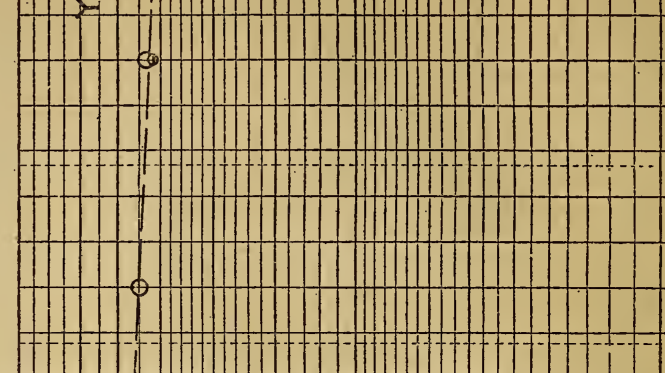

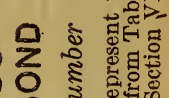

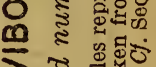

1.

है

मे :

()

of

:

突

ริ

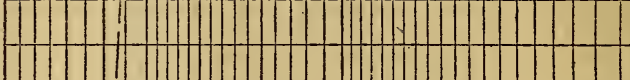

$+1010$

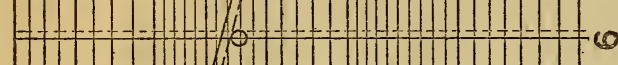

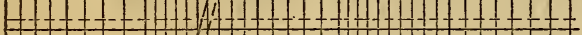
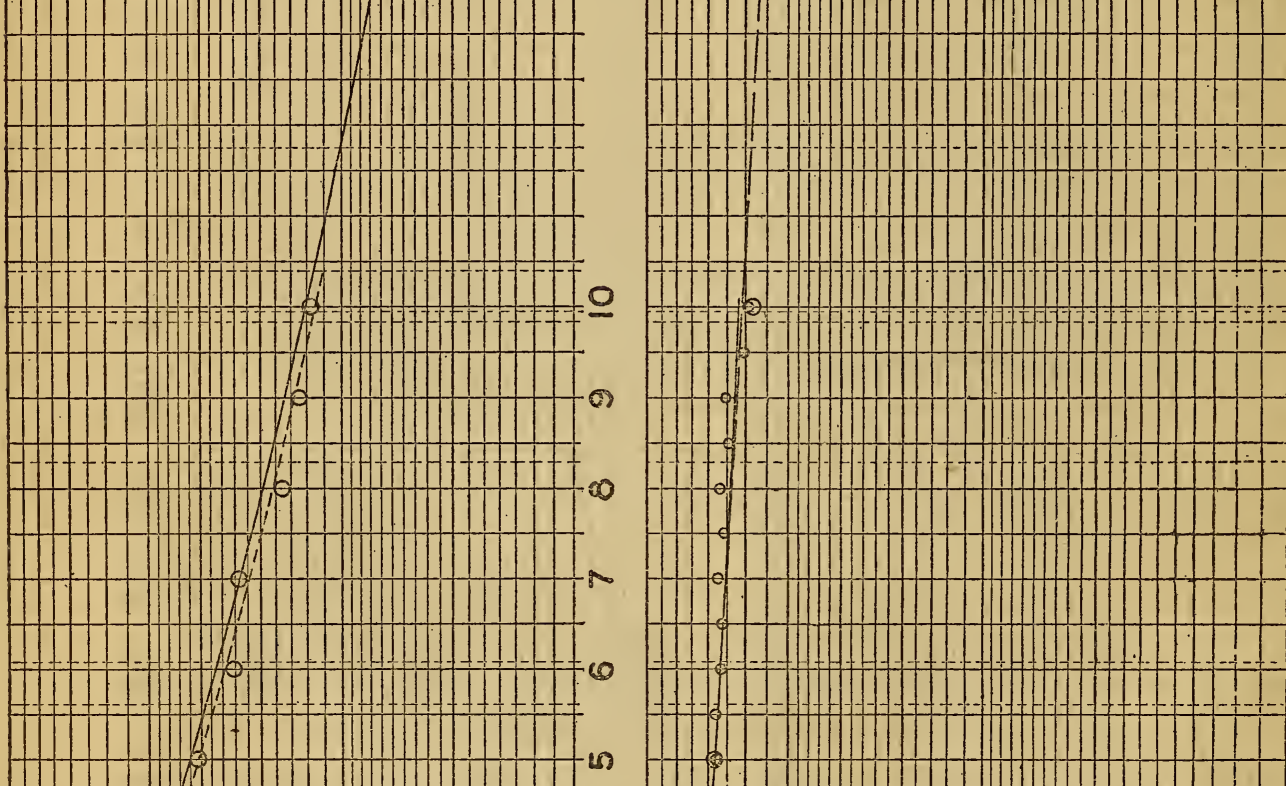

8 is

\&

충

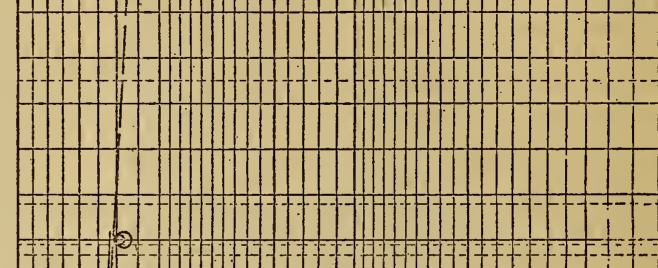

है

क्ष

$\delta$ के

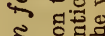

है

क्षें

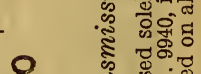

$\stackrel{\circ}{N}$
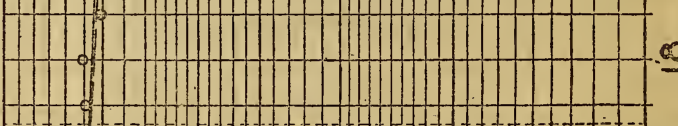

H-7 - H
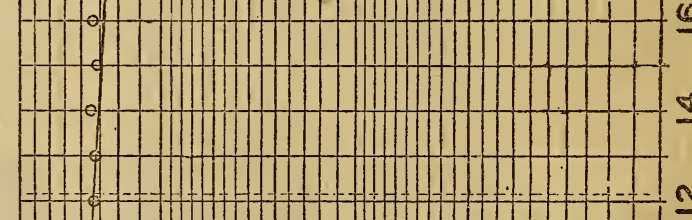

- _ I -
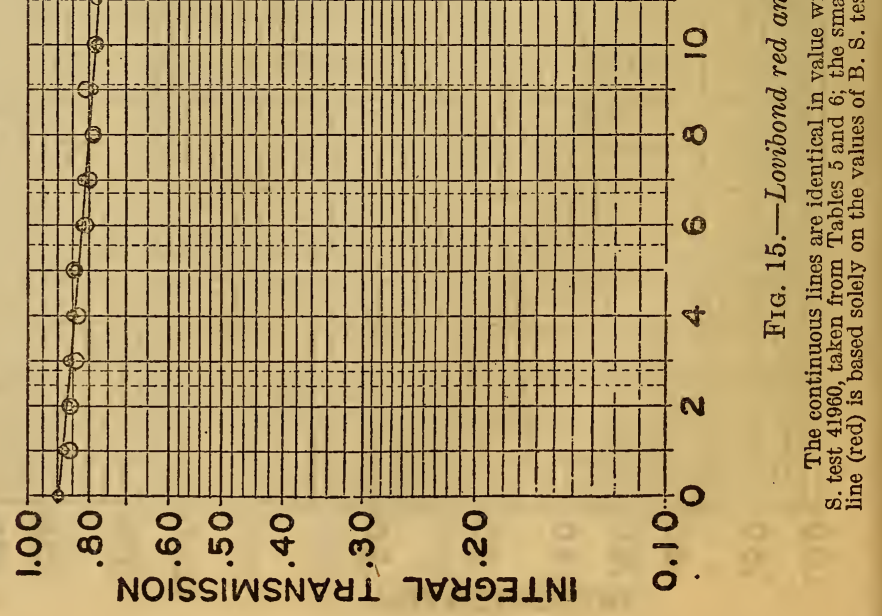